\title{
BMJ Global Health A scoping review of paediatric latent tuberculosis infection care cascades: initial steps are lacking
}

\author{
Jeffrey I Campbell, ${ }^{1}$ Thomas J Sandora, ${ }^{1}$ Jessica E Haberer ${ }^{2}$
}

To cite: Campbell Jl,

Sandora TJ, Haberer JE. A scoping review of paediatric latent tuberculosis infection care cascades: initial steps are lacking. BMJ Global Health 2021;6:e004836. doi:10.1136/ bmjgh-2020-004836

Handling editor Senjuti Saha

- Additional supplemental material is published online only. To view, please visit the journal online (http://dx.doi.org/10. 1136/bmjgh-2020-004836)

Received 22 December 2020 Revised 15 April 2021 Accepted 19 April 2021

\section{Check for updates}

(c) Author(s) (or their employer(s)) 2021. Re-use permitted under CC BY-NC. No commercial re-use. See rights and permissions. Published by BMJ.

${ }^{1}$ Division of Infectious Diseases, Department of Pediatrics, Boston Children's Hospital, Boston, Massachusetts, USA

${ }^{2}$ Center for Global Health, Massachusetts General Hospital, Boston, Massachusetts, USA

\section{Correspondence to} Dr Jeffrey I Campbell; Jeffrey.Campbell@childrens. harvard.edu

\section{ABSTRACT}

Background and objectives Identifying and treating children with latent tuberculosis infection (TB infection) is critical to prevent progression to TB disease and to eliminate TB globally. Diagnosis and treatment of TB infection requires completion of a sequence of steps, collectively termed the TB infection care cascade. There has been no systematic attempt to comprehensively summarise literature on the paediatric TB infection care cascade.

Methods We performed a scoping review of the paediatric TB infection care cascade. We systematically searched PubMed, Cumulative Index to Nursing and Allied Health Literature, Cochrane and Embase databases. We reviewed articles and meeting abstracts that included children and adolescents $\leq 21$ years old who were screened for or diagnosed with TB infection, and which described completion of at least one step of the cascade. We synthesised studies to identify facilitators and barriers to retention, interventions to mitigate attrition and knowledge gaps.

Results We identified 146 studies examining steps in the paediatric TB infection care cascade; 31 included children living in low-income and middle-income countries. Most literature described the final cascade step (treatment initiation to completion). Studies identified an array of patient and caregiver-related factors associated with completion of cascade steps. Few health systems factors were evaluated as potential predictors of completion, and few interventions to improve retention were specifically tested.

Conclusions We identified strengths and gaps in the literature describing the paediatric TB infection care cascade. Future research should examine cascade steps upstream of treatment initiation and focus on identification and testing of at-risk paediatric patients. Additionally, future studies should focus on modifiable health systems factors associated with attrition and may benefit from use of behavioural theory and implementation science methods to improve retention.

\section{BACKGROUND}

The WHO has named identification and treatment of tuberculosis (TB) infection a cornerstone of efforts to eliminate TB by $2030 .^{1}$ (note: in this article, we will use the term 'TB

\section{Key questions}

What is already known?

- Most patients at risk for latent tuberculosis infection (TB infection) do not complete the steps needed to diagnosis and treat TB infection (the 'TB infection care cascade').

- Children face unique barriers to completion of the TB infection care cascade.

What are the new findings?

- Although many studies have evaluated portions of the paediatric TB infection care cascade, they have primarily focused on the final step of the cascade: treatment initiation to treatment completion.

- Little published research has described sustainable interventions that target modifiable barriers to completing upstream steps of the paediatric TB infection care cascade.

What do the new findings imply?

- Future research should focus on early steps of the paediatric TB infection care cascade and should seek to identify and address modifiable health systems barriers to retention in the cascade.

infection' to distinguish patients with latent TB infection from those with TB disease.) The United Nations has set shorter term milestones to end the TB epidemic, including provision of TB preventive treatment (TPT) for 30 million people exposed to infectious TB and/or diagnosed with TB infection between 2018 and 2022, of whom 6.3 million received treatment in 2018-2019. ${ }^{2}$ TB infection diagnosis and treatment require completion of sequential steps, which together constitute the TB infection care cascade. ${ }^{3-11}$

A prior systematic review and meta-analysis found that more than $80 \%$ of adults and children at risk for $\mathrm{TB}$ infection do not complete the care cascade. ${ }^{3}$ Several studies have found that children face different barriers and complete one or more cascade steps at different rates than adults. ${ }^{12-20}$ Yet two prior systematic reviews of the $\mathrm{TB}$ infection 
care cascade have either excluded children or did not distinguish the unique challenges paediatric patients face. ${ }^{3} 21$ The full TB infection cascade is not always needed-existing guidance recommends that child contacts $<5$ years old and people living with HIV exposed to infectious TB can be started on TPT following a clinical exam without preceding TB infection testing. ${ }^{22} \mathrm{~A}$ focused systematic review of contact case management of child contacts of individuals with infectious TB in high burden countries identified health system (eg, lack of protocols and lack of healthcare worker (HCW) education), structural (eg, cost of transport) and patient/family level barriers to completing evaluation for $\mathrm{TB}$ and initiation/ completion of TPT. ${ }^{23}$ Because of heterogeneity in TB screening guidelines between countries, and because testing is not always needed for contact case management in high burden countries, that review did not examine gaps in TB infection diagnosis in detail. However, even in high TB burden settings, strengthening testing pathways will help to avoid unnecessary TPT, improve acceptability of treatment and expand treatment beyond close contacts. $^{24}$

We performed a scoping review of paediatric TB infection care cascade literature with a goal of understanding facilitators and barriers to care for children evaluated and treated for TB infection. We sought to understand the cascade in both high and low resource areas and in the full range of clinical care and research settings. We defined seven steps of the care cascade, based on the cascade outlined by Alsdurf and colleagues: (1) intention to test to receipt of the test (tuberculin skin test (TST) or interferon gamma release assay (IGRA)), (2) receipt of test to test read, (3) test read to referral for medical evaluation, (4) referral for medical evaluation to completion of medical evaluation, (5) completion of medical evaluation to treatment recommendation, (6) treatment recommendation to treatment start and (7) treatment start to treatment completion (figure 1). ${ }^{325}$

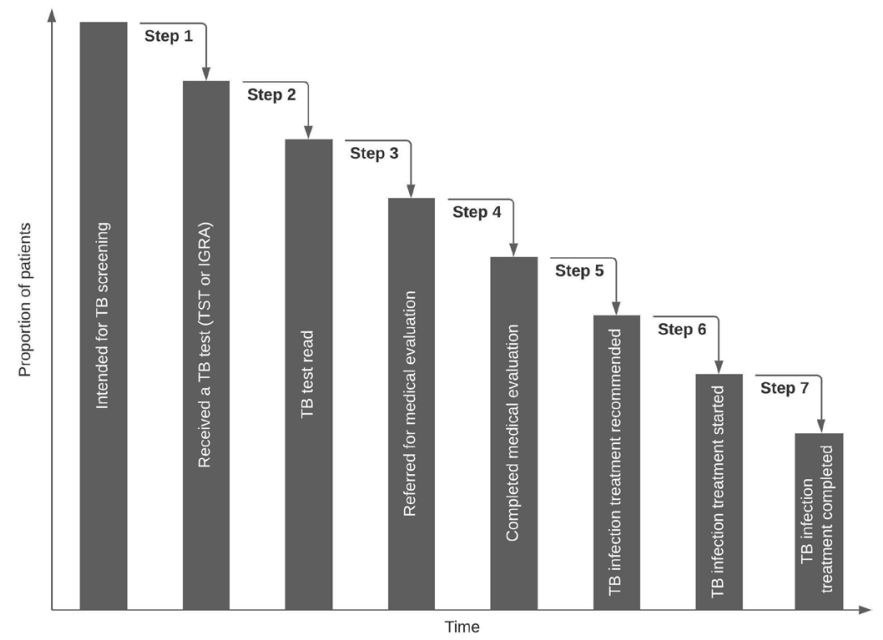

Figure 1 Schema of the TB infection care cascade (bars not to scale). IGRA, interferon gamma release assay; TB, tuberculosis; TST, tuberculin skin test.
Our study complements the prior review of the contact case management approach used in many LMIC $^{23}$ by including studies from low-burden settings and focusing in detail on diagnostic steps of the cascade.

\section{METHODS}

\section{Scoping review questions}

The questions we sought to answer in this scoping review were:

1. What are barriers and facilitators of paediatric TB infection care cascade completion in high-income and low-income and middle-income (LMIC) countries?

2. What strategies have been employed to improve retention in the paediatric TB infection care cascade?

3. What key knowledge gaps remain in literature about the paediatric TB infection care cascade?

\section{Population, concept and context}

We included articles and meeting abstracts that specifically described: (1) children or adolescents; (2) patients screened for or diagnosed with TB infection; and (3) completion of at least one step of the care cascade.

The population of interest in this review was paediatric patients tested for and diagnosed with TB infection. We defined paediatric patients as patients age $0-21$ years old; we further defined 'children' as patients aged $0-11$ years old and 'adolescents' as 12-21 years old. We focused on patients tested for TB infection (ie, who had undergone a TB infection test using a TST or IGRA). However, to retain a broad view of TB infection diagnosis and treatment in high-burden settings, we included studies that reported on child contacts $<5$ years old receiving TPT following exposure to infectious TB who had not received a TB infection test, when those children were grouped with paediatric patients diagnosed with TB infection (ie, who had a positive TB infection test).

The key concepts in this review were facilitators and barriers to completion of one or more cascade steps and interventions designed to improve retention. Reporting of a specific step of the cascade was defined as reporting the number of patients that started and completed the step. Assignment of steps in the cascade was based on data as reported in each study. When ambiguous, proper assignment was determined by our interpretation of the reported data. We defined barriers and facilitators as factors that were statistically associated with completion of one or more cascade steps or that authors causally linked to completion of a step. For example, adverse medication effects that caused patients to discontinue TPT, as reported by study authors, were considered barriers to cascade completion, even if no statistical test was done. For facilitators and barriers that were statistically associated with completion, we focused on factors that were significant in multivariable analyses and that were specifically found to affect paediatric patients. We defined interventions as programmes, 
strategies or activities designed to prevent loss from one or more step of the care cascade. Because our goal was to understand the range of interventions targeting cascade retention, we included descriptions of interventions even when efficacy was not evaluated within a study.

The context of this review was all clinical and geographic settings in which TB infection care was provided. Articles and abstracts were excluded if they were not written in English, Spanish, French or German.

\section{Search strategy}

We systematically searched PubMed, Embase, CINAHL and Cochrane for terms related to the TB infection care cascade in children and adolescents, including terms pertinent to latent TB infection, children and adolescents, and specific steps of the care cascade (full search strategy in online supplemental appendix 1). The initial database searches were performed on 10 February 2020 and updated on 13 November 2020. We did not restrict the timeframe of publications.

\section{Data extraction}

We collected all references using EndNote V.7.7 and imported them into Covidence. We screened titles and abstracts for eligibility and obtained full texts of articles and abstracts meeting criteria. Using a standardised data sheet, one reviewer (JIC) extracted publication year, country, number of children and adolescents included, inclusion of children $<5$ years old, population, care cascade steps reported, number of patients completing specified care cascade steps, reasons for non-completion of steps, factors statistically associated with step completion, interventions used to improve retention, behavioural theories used for intervention design and treatment used. Studies that reported multiple steps of the care cascade were included in the synthesis of each relevant step. Data were tabulated, summarised and categorised to identify themes and gaps in the literature.

We used the Preferred Reporting Items for Systematic reviews and Meta-Analysis extension for Scoping Reviews to guide data reporting. ${ }^{26}$ Because of heterogeneity in study type, objectives and use of interventions, we did not perform formal quality assessments, an approach commonly used in scoping reviews. ${ }^{27}$ Patients and public were not involved in the design or conduct of this study.

\section{RESULTS}

We identified 146 studies examining steps in the TB infection care cascade for children and adolescents, including 143 primary analyses and 3 systematic reviews (figure 2 and table 1). Of included studies, 31 included children and adolescents living in LMIC (table 2). Twenty-one studies reported comparative effectiveness of interventions to promote retention in at least one cascade step.

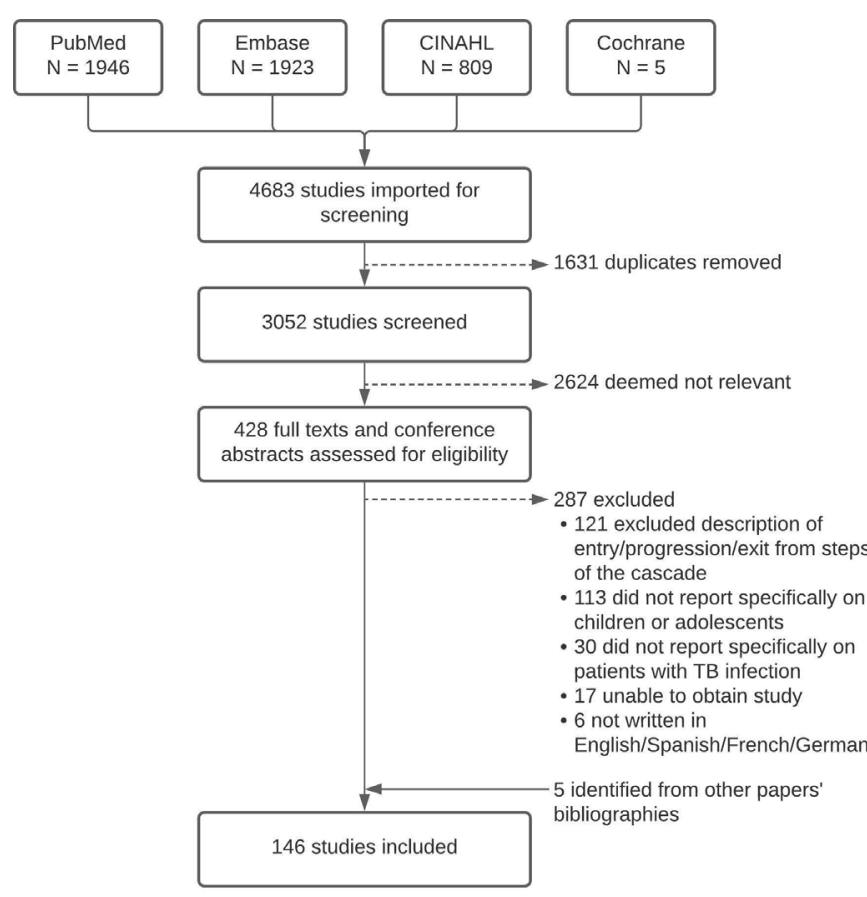

Figure 2 PRISMA diagram of evaluated and included studies. CINAHL, Cumulative Index to Nursing and Allied Health Literature; PRISMA, Preferred Reporting Items for Systematic Reviews and Meta-Analyses; TB, tuberculosis.

Table 3 summarises barriers, facilitators, interventions tested and knowledge gaps.

Eight studies included in this review reported on paediatric patients living with HIV. ${ }^{28-35}$ Of these, HIV seroprevalence was high $(23.5 \%)$ in one study, which reported on children and adolescents starting TPT in Brazil..$^{30}$ In the remainder, HIV seroprevalence was relatively low $(0.8 \%-$ $4.5 \%)$. Facilitators and barriers to cascade completion in children and adolescents with HIV were not analysed separately in any included study.

\section{The complete care cascade}

We identified seven studies that documented completion of all seven cascade steps. ${ }^{28}{ }^{36-41}$ These studies described the cascade within specific scenarios: school-based screenings, ${ }^{39} 40$ screening among asylum seekers ${ }^{37}$ and contact investigations..$^{28} 363841$ The proportion of paediatric patients who completed or appropriately exited the care cascade ranged from $65 \%$ in a large study of US high school students ${ }^{39}$ to $100 \%$ in a small Australian contact tracing study. ${ }^{41}$ Only one study, which described contact tracing in Uganda, was conducted in a resource-limited setting. ${ }^{28}$ We identified a single study that used the overarching care cascade framework to design interventions for retention. This cluster-randomised trial of health centres in five countries (Canada, Benin, Ghana, Indonesia and Vietnam), named ACT4, used locally developed interventions to address specific identified barriers to retention. ${ }^{42}$ Effective strategies reported to date from this trial-from Ghana-included provision of financial support to patients, education from HCWs, home visits and decreased wait times at clinics. ${ }^{43}$ 


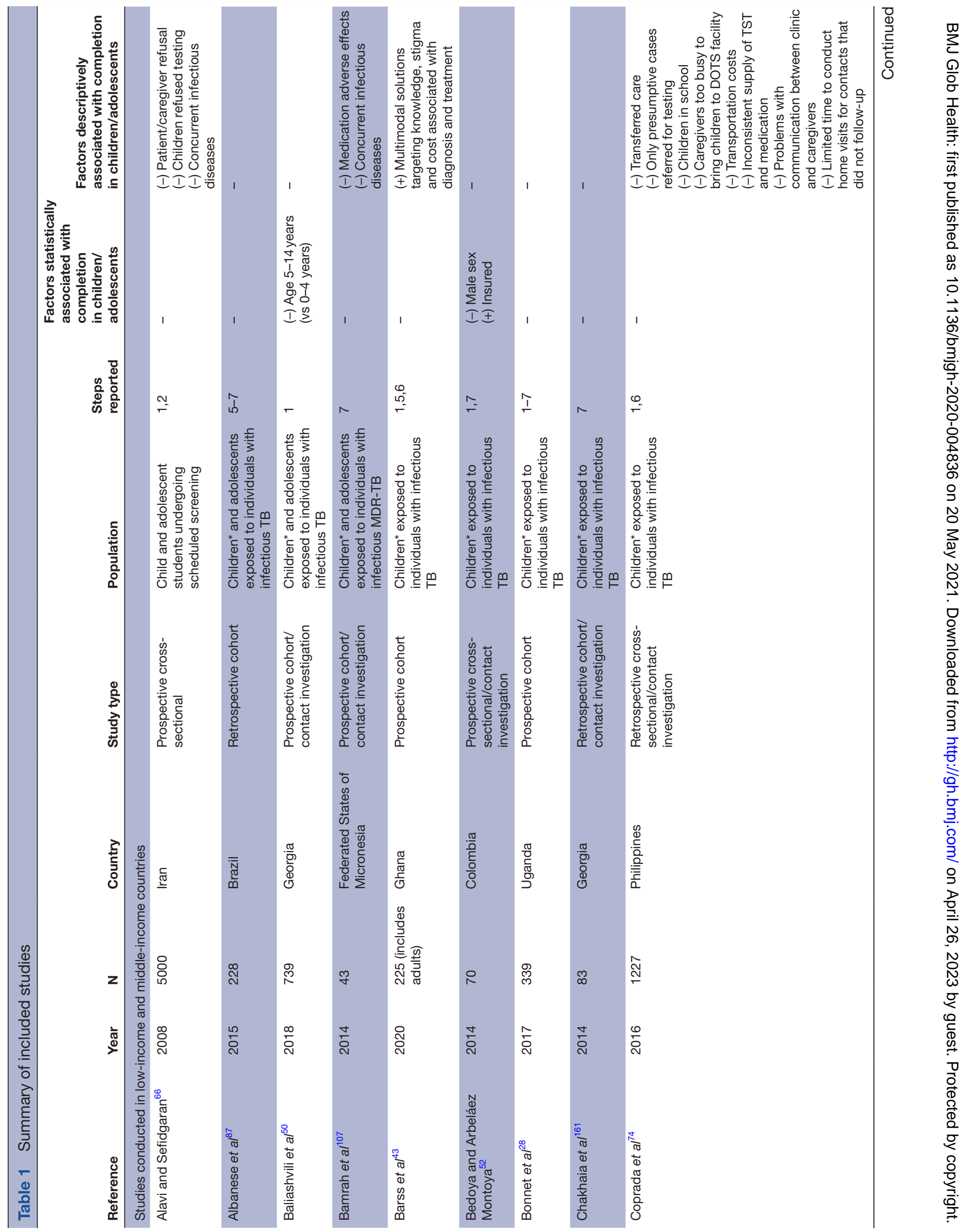




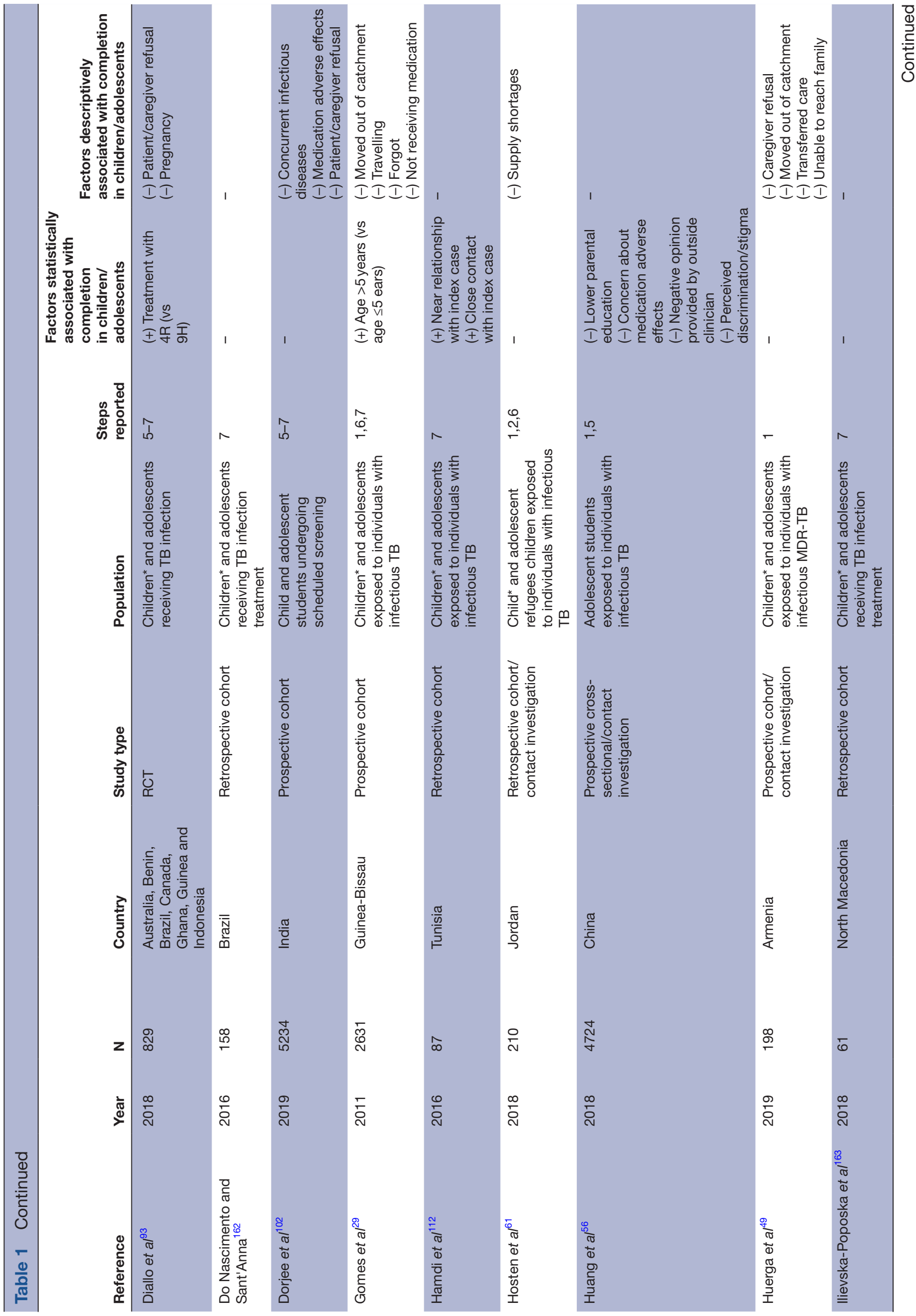

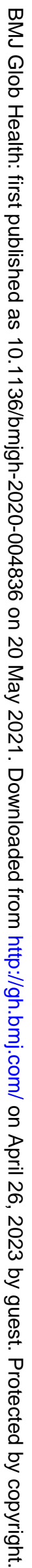



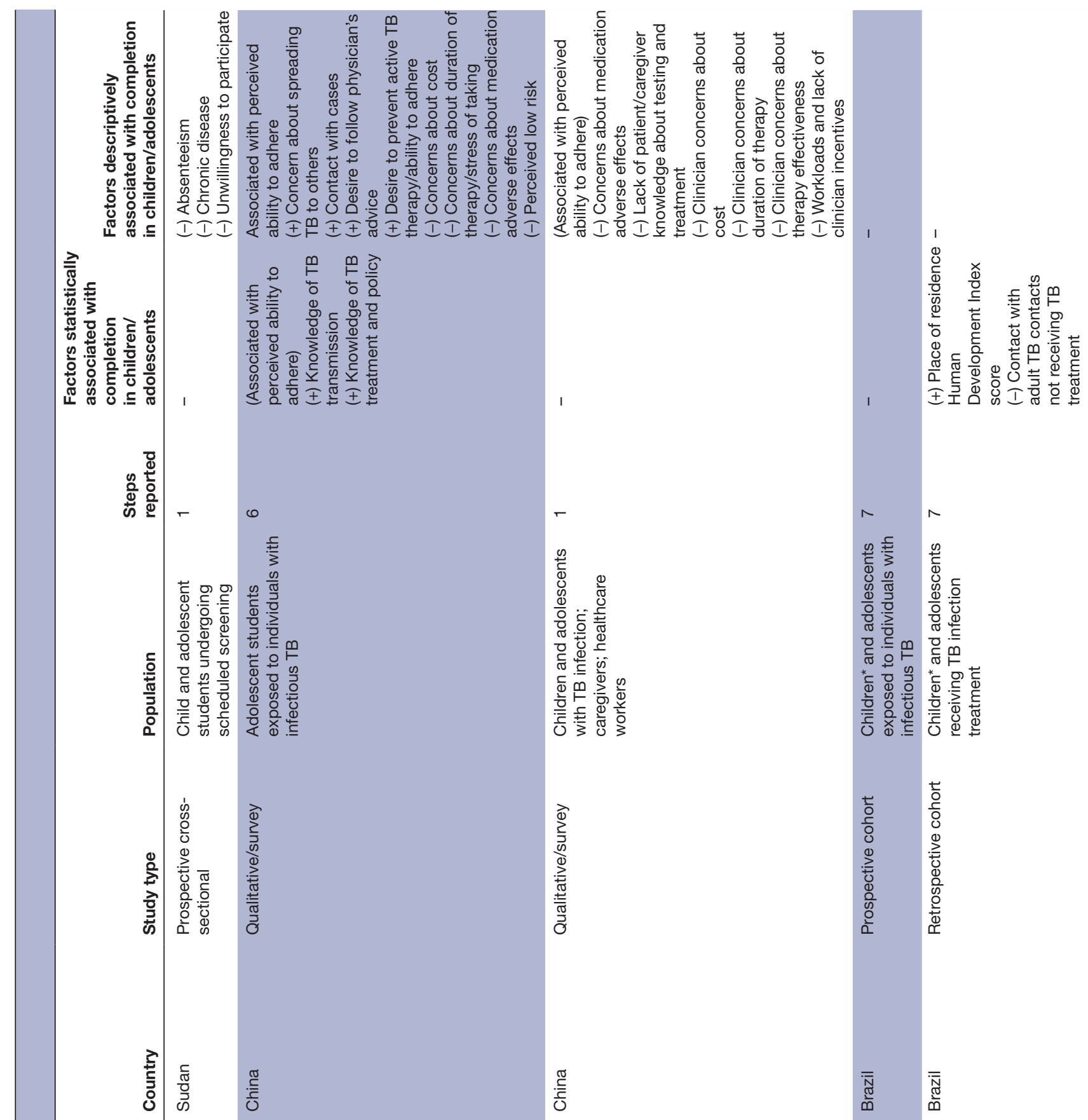

(1)

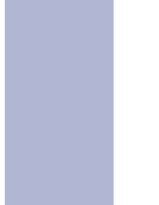

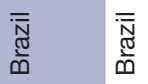

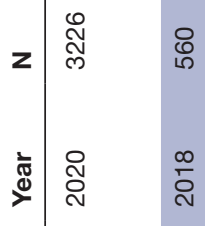




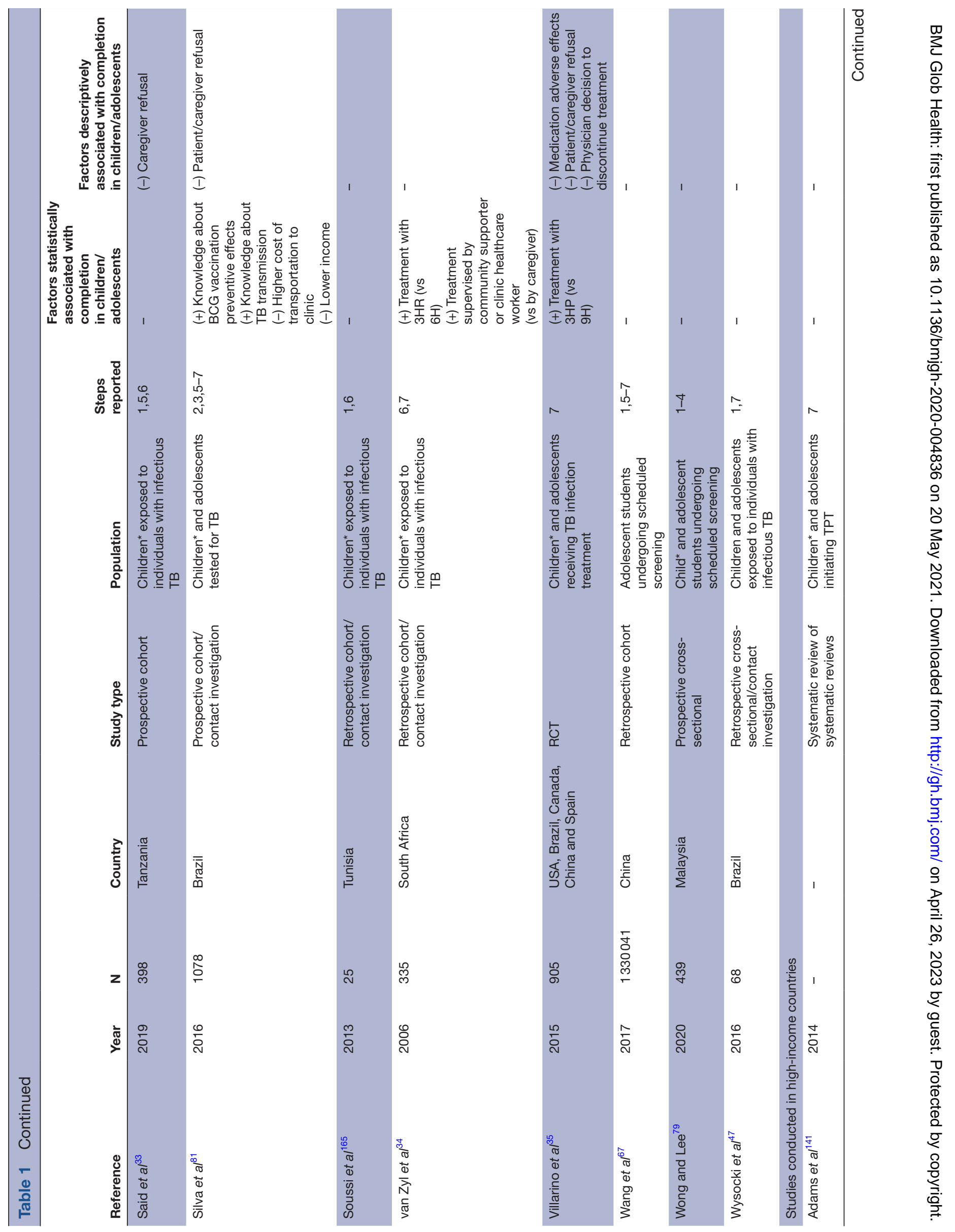




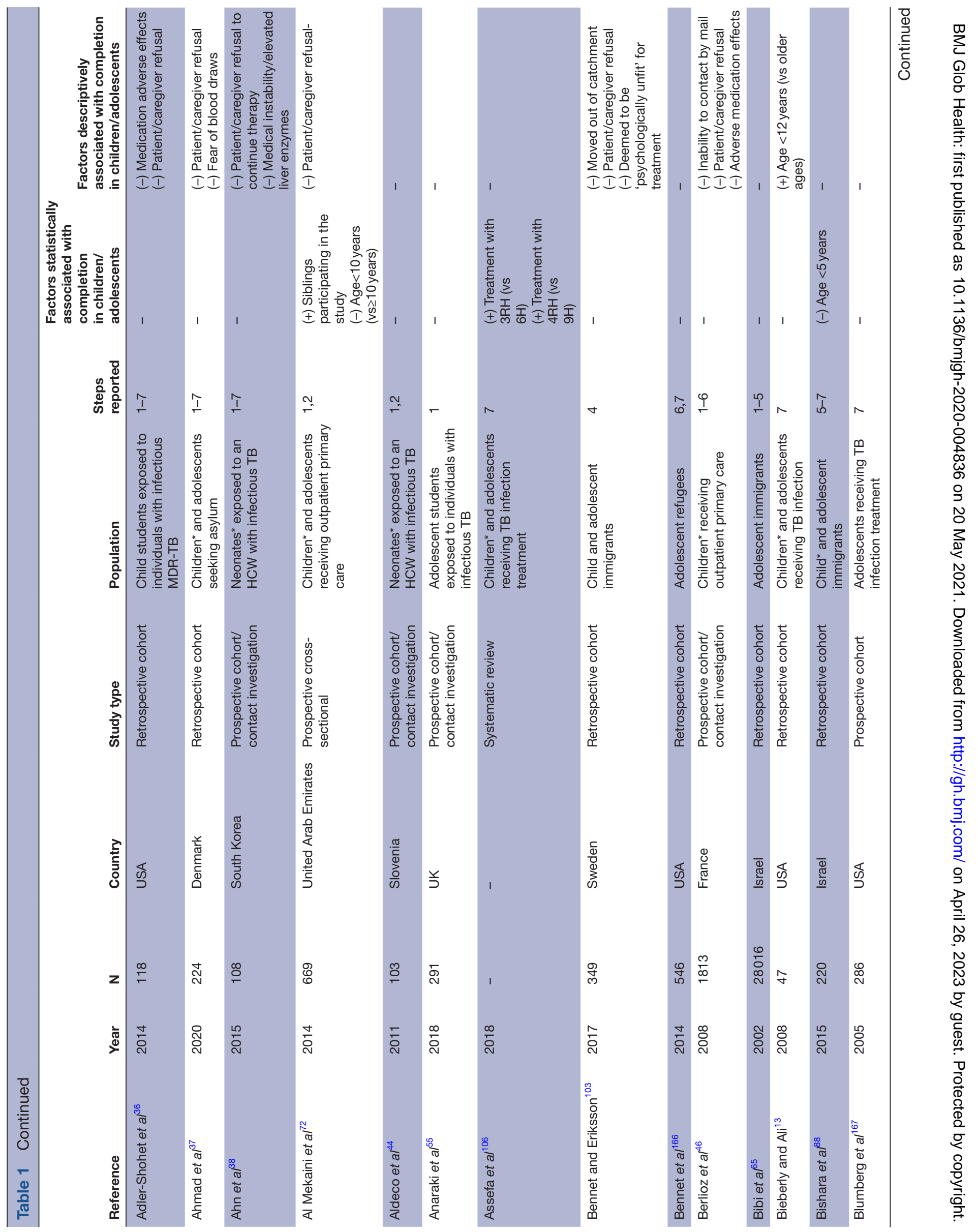




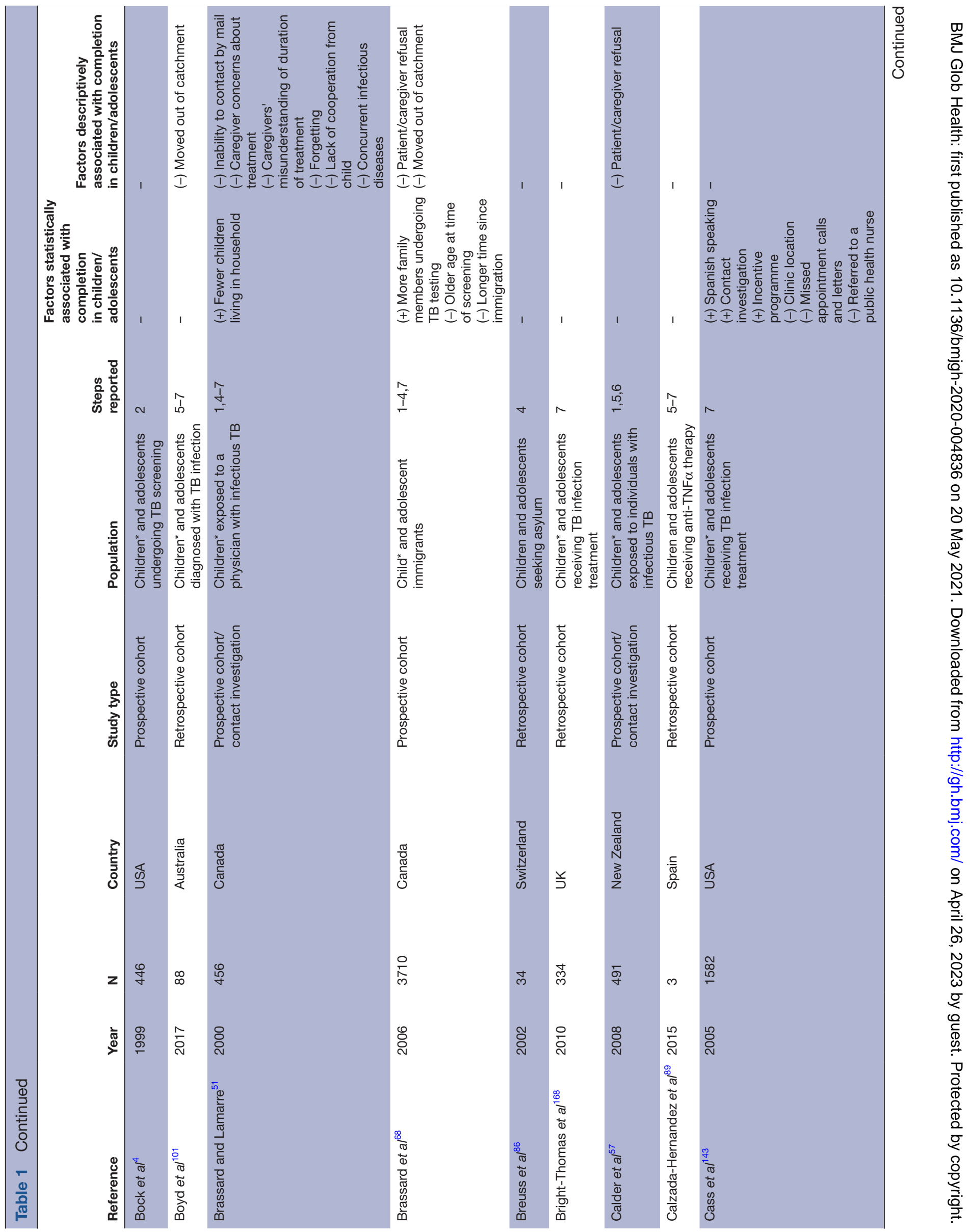




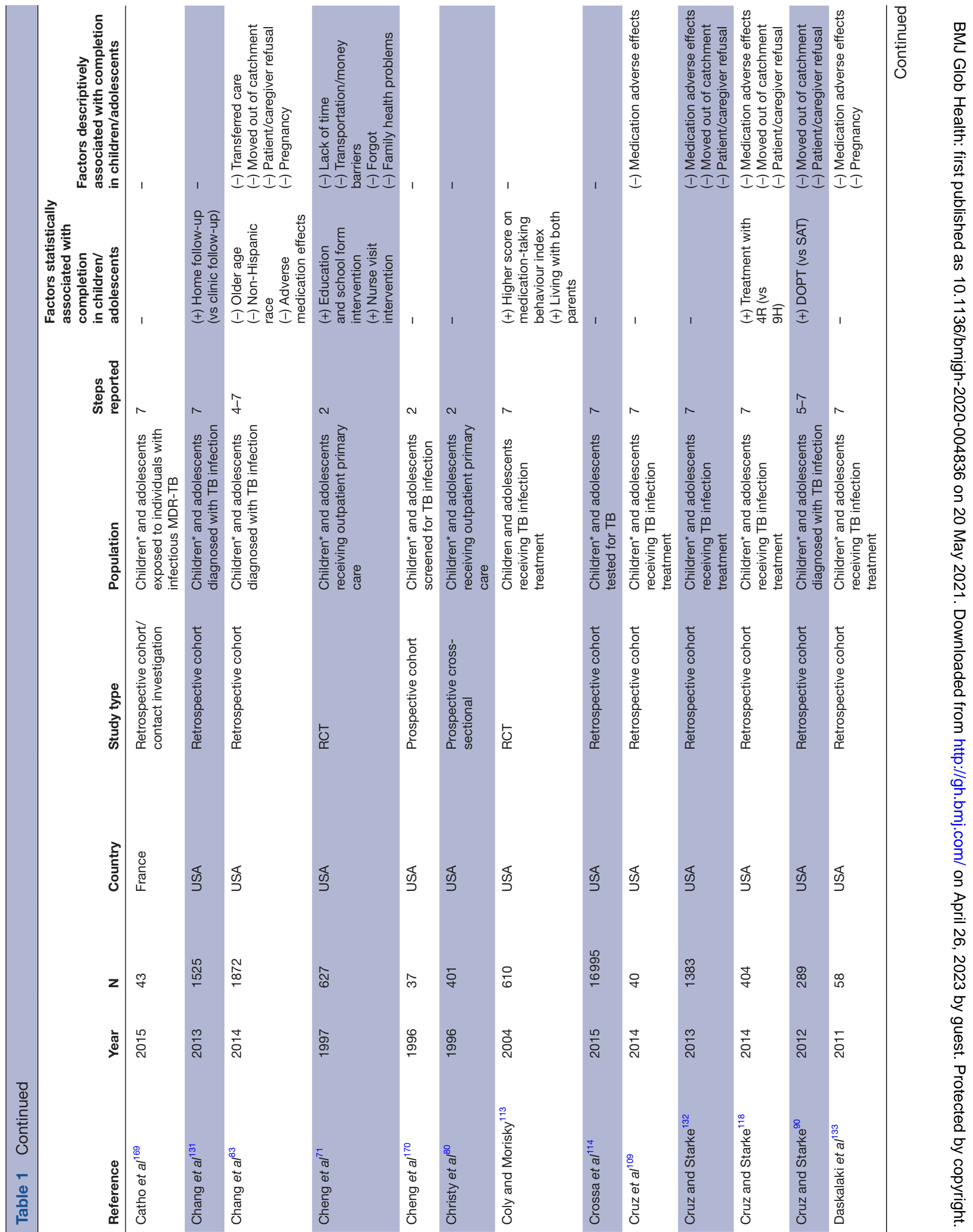




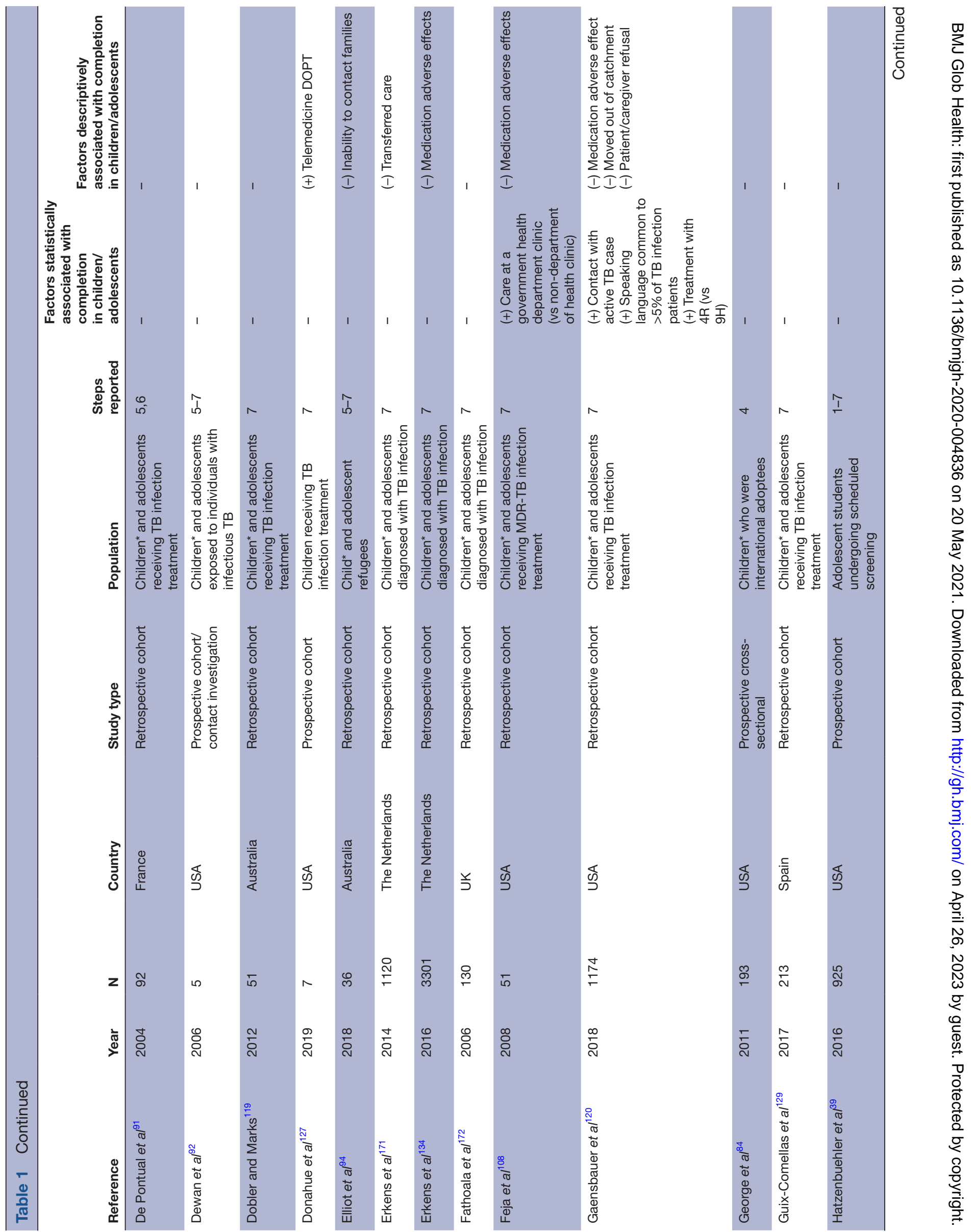




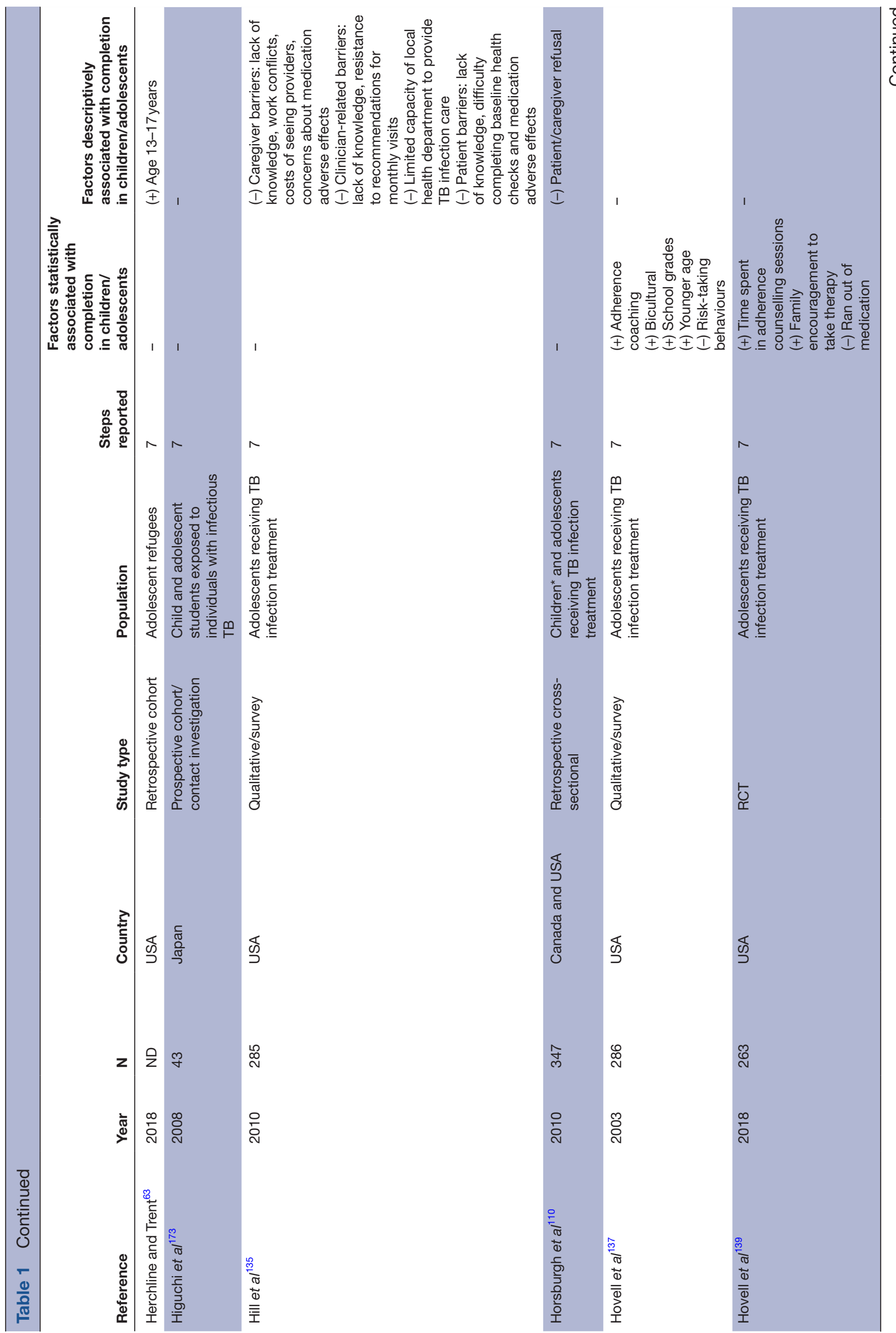




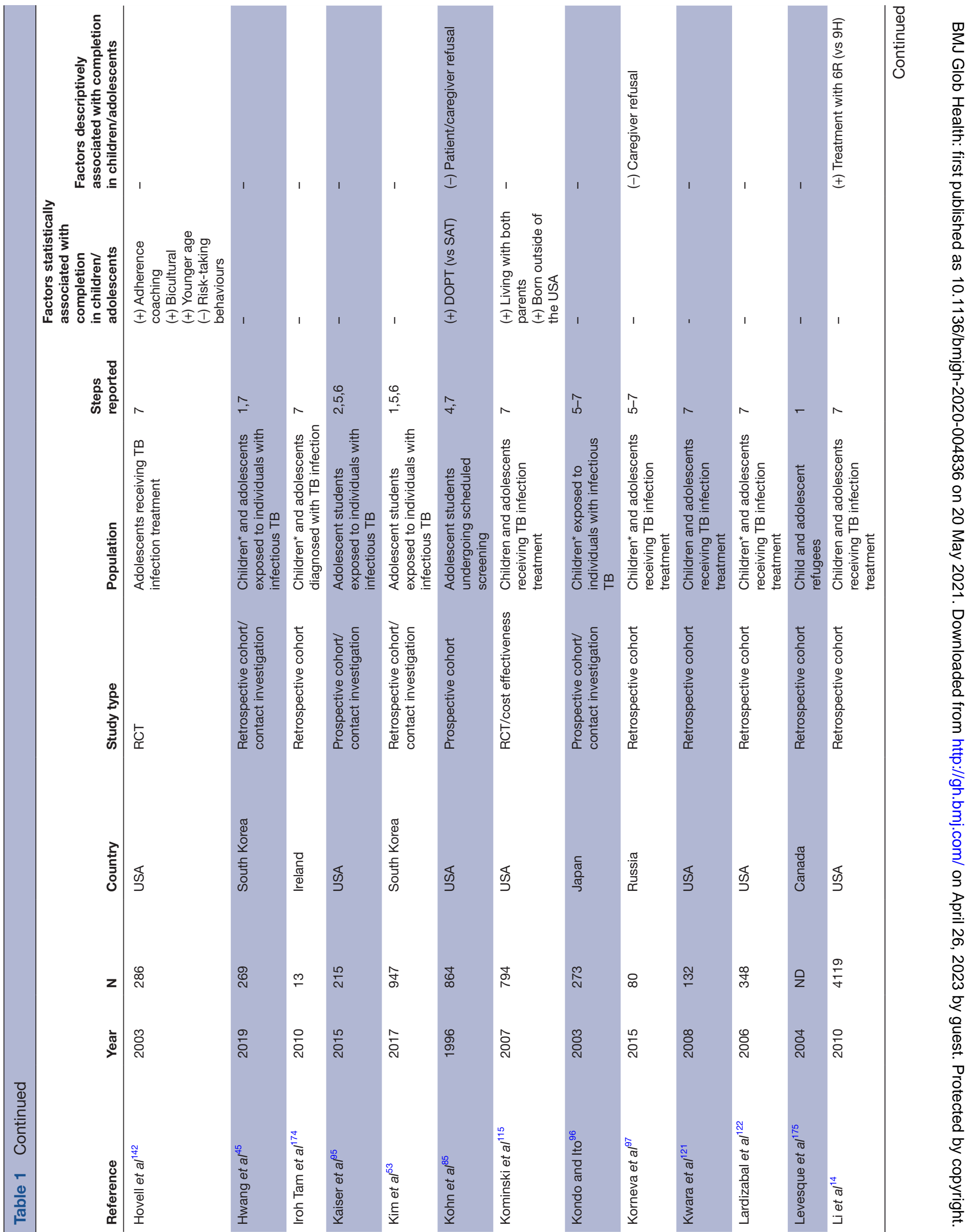




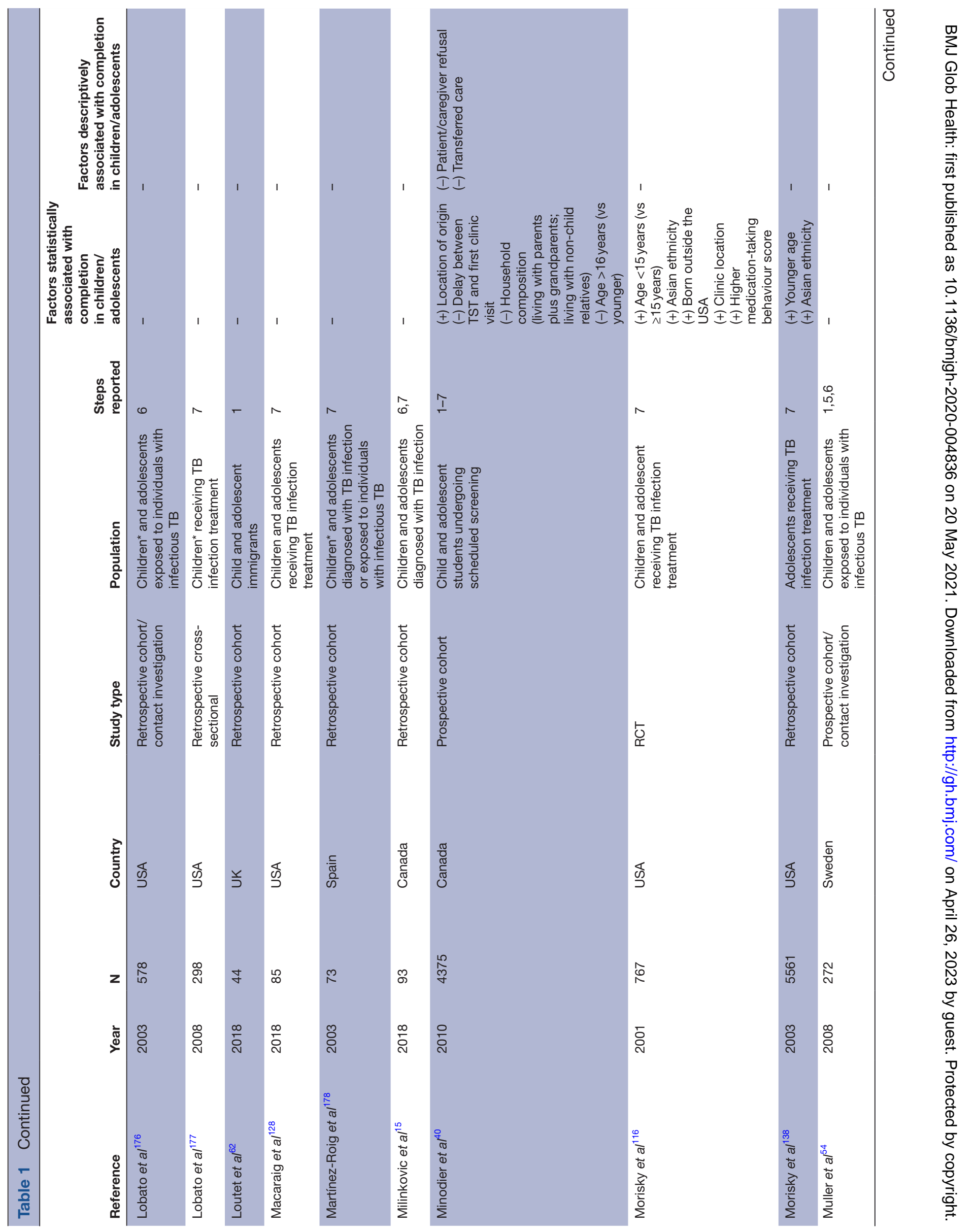




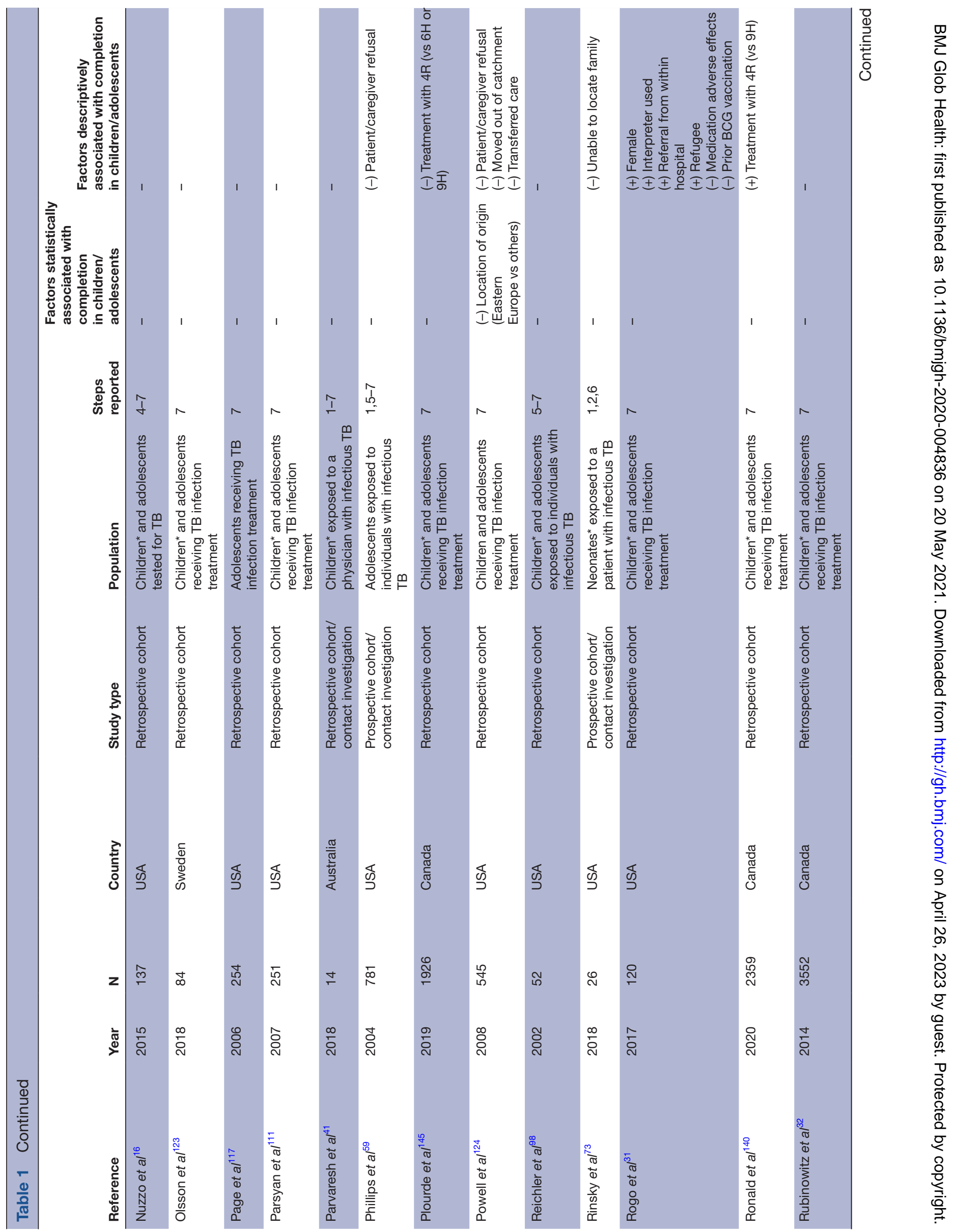




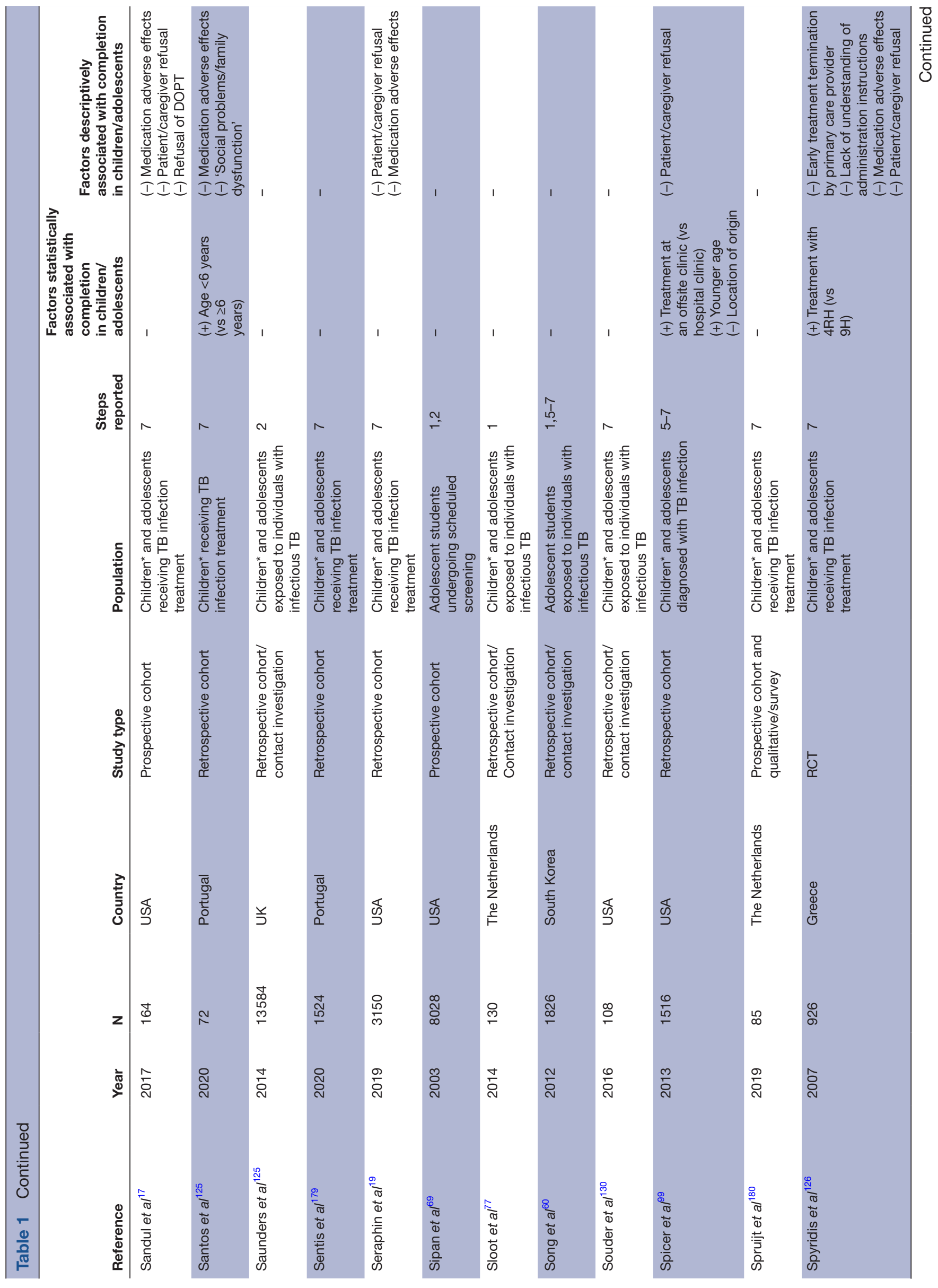

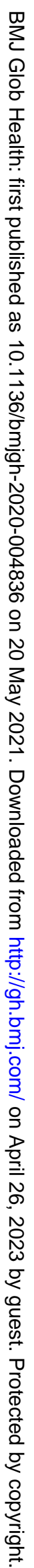




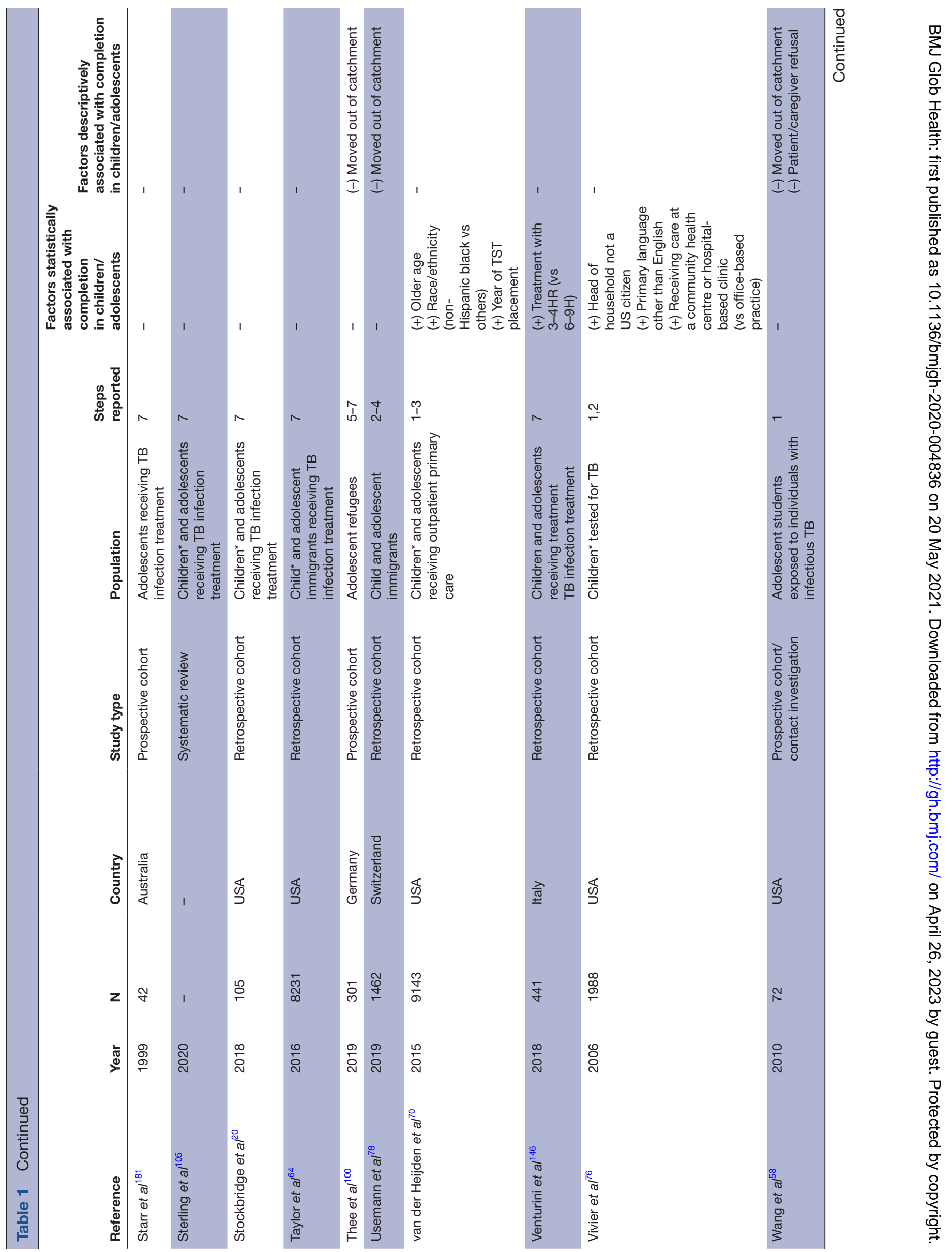


Table 2 Characteristics of included studies

\begin{tabular}{lc}
\hline Study characteristics & Number of studies \\
\hline Total included studies & 146 \\
\hline Year published & \\
\hline Before 2001 & 7 \\
\hline $2001-2010$ & 45 \\
\hline $2011-2020$ & 94 \\
\hline Study type & \\
\hline Systematic review & 3 \\
\hline $\begin{array}{l}\text { Retrospective cohort/cross-sectional } \\
\text { studies }\end{array}$ & 84 \\
\hline Cohort studies & 67 \\
\hline Cross-sectional studies & 2 \\
\hline $\begin{array}{l}\text { Contact investigations (cohort+cross- } \\
\text { sectional) }\end{array}$ & 15 \\
\hline $\begin{array}{l}\text { Prospective cohort/cross-sectional studies } \\
\text { Cohort studies }\end{array}$ & $46^{*}$ \\
\hline $\begin{array}{l}\text { Cross-sectional studies } \\
\text { Contact investigations (cohort+cross- } \\
\text { sectional) } \\
\text { Randomised trials }\end{array}$ & 20 \\
\hline $\begin{array}{l}\text { Qualitative/survey } \\
\text { Included patients living in low-income and } \\
\text { middle-income countries }\end{array}$ & 31 \\
\hline
\end{tabular}

middle-income countries

\begin{tabular}{|c|c|}
\hline \multicolumn{2}{|l|}{ Care cascade steps } \\
\hline 1 - Intended for testing $\rightarrow$ initial testing & 44 \\
\hline 2 - Initially tested $\rightarrow$ received test result & 27 \\
\hline $\begin{array}{l}3 \text { - Received test result } \rightarrow \text { referral for } \\
\text { evaluation }\end{array}$ & 15 \\
\hline $\begin{array}{l}4 \text { - Referral for evaluation } \rightarrow \text { completion of } \\
\text { evaluation }\end{array}$ & 20 \\
\hline $\begin{array}{l}5 \text { - Completion of evaluation } \rightarrow \\
\text { recommendation for treatment }\end{array}$ & 39 \\
\hline $\begin{array}{l}6 \text { - Recommendation for treatment } \rightarrow \\
\text { initiation of treatment }\end{array}$ & 47 \\
\hline $\begin{array}{l}7 \text { - Initiation of treatment } \rightarrow \text { completion of } \\
\text { treatment }\end{array}$ & 105 \\
\hline 1-7 - Entire cascade & 7 \\
\hline $\begin{array}{l}\text { Comparative effectiveness studies targeting } \\
\text { retention in the cascade }\end{array}$ & 21 \\
\hline
\end{tabular}

${ }^{*}$ One study ${ }^{180}$ presented results of both a prospective cohort and qualitative/survey analysis.

\section{Step 1: intended for testing $\rightarrow$ received a test}

Twenty-two studies documented screening of paediatric patients at high risk of TB infection because of exposure in healthcare settings, ${ }^{3844}$ the community ${ }^{28} 29334145-52$ and schools. ${ }^{36}{ }^{53-60}$ Additionally, 12 studies reported screening groups with a high population prevalence of TB infection, such as newly arrived asylum seekers, immigrants and refugees, ${ }^{37}$ 61-64 and students from high-risk populations. ${ }^{39} 4065-69$ Three studies reported on primary care based screening-two from the USA $^{70} 71$ and one from the United Arab Emirates ${ }^{72}$-all of which used risk 


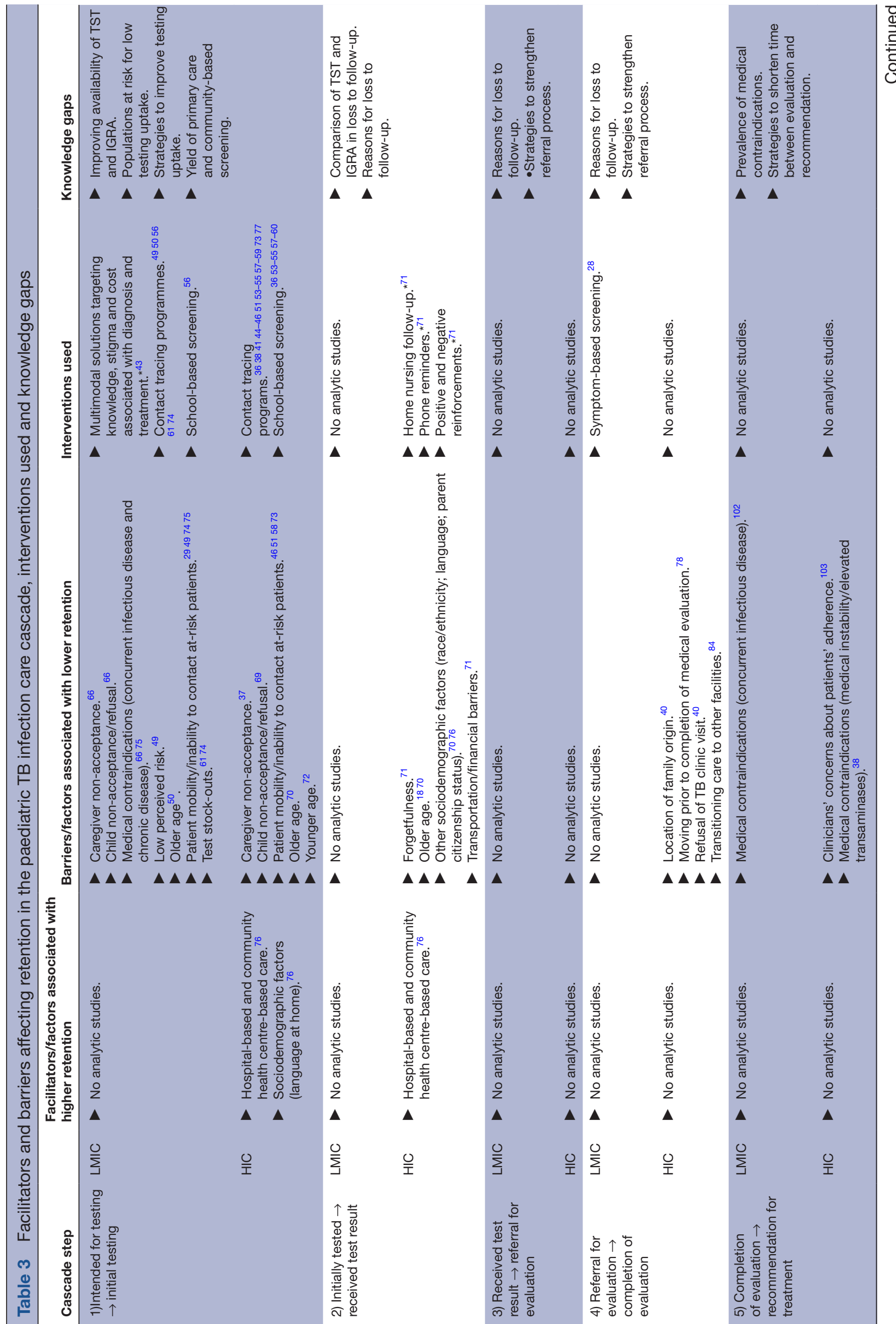

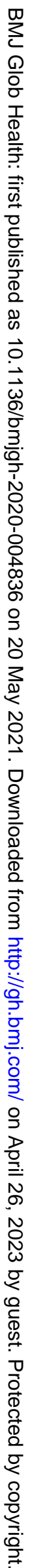




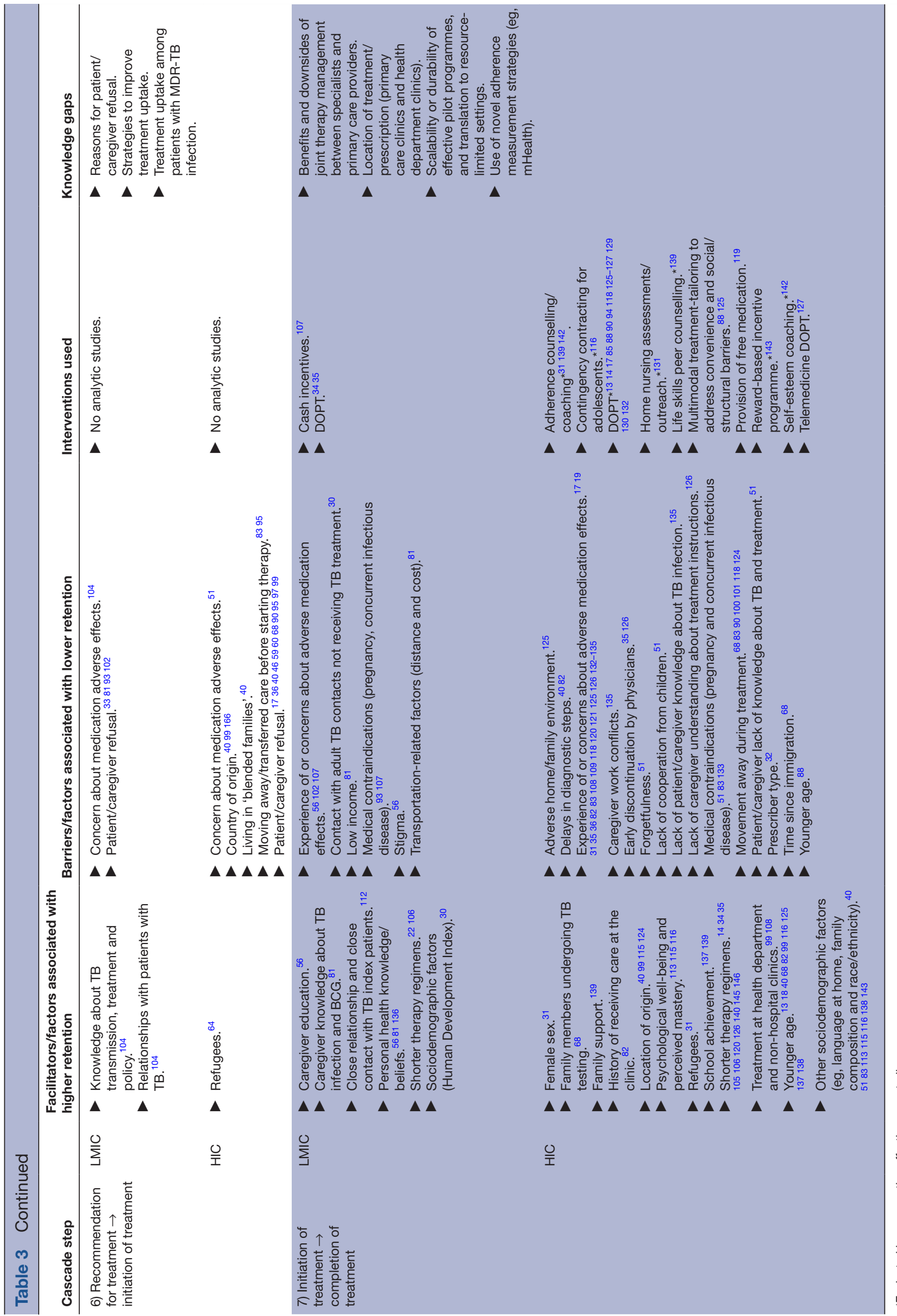


screening questionnaires to identify paediatric patients for testing. Completion of testing varied widely, ranging from $28 \%{ }^{52}$ to $100 \%$. $^{36384144}$

Several barriers to testing were common to high-income countries and LMICs. Lack of acceptability among caregivers for TST and IGRA often precluded testing, due to factors such as fear of blood draws (as in a cohort of asylum seekers in Denmark) ${ }^{37}$ and 'parental avoidance' in Iran.$^{66}$ Low perceived risk also motivated caregivers to decline testing for their children. ${ }^{49}$ Children also refused testing. ${ }^{66}{ }^{69}$ For example, among 5000 schoolchildren intended for testing in Iran, 220 'ran away from the team before they could be tested ${ }^{66}$ Contacting at-risk children and adolescents proved challenging in both highincome countries and LMICs. At-risk patients were often highly mobile, and families could be difficulty to contact or locate. ${ }^{29} 464951$ 73-75 Additional patient/family-related factors that have been statistically associated with lack of testing included both older age ${ }^{5070}$ and younger age, ${ }^{72}$ and presence of comorbidities. ${ }^{6675}$

Logistical and health system challenges to testing differed between high-income countries and LMICs. In LMIC, stock-outs of tuberculin limited ability to perform TSTs. ${ }^{61} 74$ Meanwhile, the setting of primary care delivery was found to affect testing uptake in the USA. ${ }^{76}$

A number of studies in high-income countries and LMICs used contact tracing and targeted schoolbased screening to facilitate uptake of TB infection testing. $36384144-46$ 49-51 53-61 737477 Only one study specifically tested interventions to improve testing uptake-the aforementioned ACT4 cluster randomised trial, which found that a multimodal strategy increased identification and testing of paediatric contacts from a preintervention baseline in Ghana. ${ }^{43}$

\section{Step 2: received a test $\rightarrow$ test read}

Twenty-seven studies documented completion of the second cascade step. All studies that presented completion of initial TB testing procedures used the proportion of TSTs that were read as their outcome. No studies documented methods to deliver IGRA results to patients or follow-up indeterminate IGRA results. Return for TST reading was mainly described in three contexts: (1) programmatic evaluations of school-based TB infection screening and treatment programmes 396568697879 ; (2) non-school-based contact investigations ${ }^{28} 3844466173$; and (3) primary care clinics. ${ }^{70} 717680$ Most studies demonstrated high rates of return $(>90 \%)$ following TST placement, ${ }^{283638404446616581}$ although three studies conducted in primary care clinics in the USA documented lower return rates $(58 \%-84 \%) .^{70} 7180$

No studies from LMIC reported specific facilitators or barriers to completion of the step. Four studies from high-income countries evaluated associations with TST reading, finding that demographic and care delivery related factors affected retention in this step of the cascade. A study of primary care patients in the USA noted that transportation-related and financial barriers precluded TST reading for some patients. ${ }^{71}$ One contact investigation of individuals exposed to adults with $\mathrm{TB}$ in the UK found that patients $<16$ years old were more likely than patients $16-64$ years old to complete TB infection screening. ${ }^{18}$ A study of paediatric patients screened for TB infection in a primary care practice in the USA found that TST non-completion was associated with nonHispanic black race (vs other race/ethnicity), older age and earlier year of TST placement. ${ }^{70}$ Finally, young children enrolled in Medicaid in the USA had higher TST read rates if a parent was not a US citizen, if the primary language at home was not English or if care was delivered at a hospital-based clinic or community health centre (vs office-based clinic). ${ }^{76}$

We identified one study that examined strategies to improve return for TST reading, which was conducted among paediatric patients attending a US primary care clinic. ${ }^{71}$ In this study, families were randomised to one of five groups, including positive and negative reinforcement groups, and a home nurse-visit TST-reading group. Rates of TST reading in all groups, including control, were higher than in a prestudy baseline, which the authors suggest may have reflected a Hawthorne effect. The highest rate of return was $84 \%$ in the home TST reading group, although this study arm was discontinued early due to logistical challenges with the visiting nurses.

\section{Step 3: test read $\rightarrow$ referred for medical evaluation}

Fifteen studies documented completion of the third cascade step. In both high-income countries and LMICs, referral after a positive test occurred through contact investigations $^{28} 3638414681$ and mass screenings at schools with at-risk students, ${ }^{39} 4065687879$ primary care clinics in the USA $^{70} 82$ and among asylum seekers in Denmark. ${ }^{37}$ All studies documented high rates of referral $(>97 \%)$. Though most referrals occurred when screening tests returned positive, two studies reported obtaining chest radiographs prior to referral. ${ }^{3870}$ Of note, patients in most studies did not require referrals, because initial testing and subsequent medical evaluation were frequently conducted within a single care setting or by the same clinician. No studies from either high-income countries or LMICs assessed independent predictors, facilitators or barriers to referral or explored interventions targeting the referral process.

\section{Step 4: referred for medical evaluation $\rightarrow$ completed medical evaluation}

Twenty studies documented completion of the fourth cascade step. Most included studies defined the completion of medical evaluation as receiving a clinical exam and chest radiograph to exclude active TB after a positive TB infection test. Rates of medical evaluation completion were generally high $(>90 \%),{ }^{283638-414651787982-85}$ although five studies documented rates $<90 \%$. $^{16} 37656886$ Notably, one study of nurse-led, school-based screening among an immigrant population in Israel found that only $29 \%$ of paediatric patients completed medical examinations. ${ }^{65}$ 
Studies from high-income countries identified several barriers to evaluation completion. Family movement prevented completion of evaluation in two studies. ${ }^{78} 84$ Movement included transitions of care to outside clinics, which disrupted documentation of evaluation completion, as in a study of international adoptees in the USA. ${ }^{84}$ Movement also consisted of migration out of catchment areas, as in a review of a school-based TB screening programme in Switzerland, in which 2 of 21 paediatric patients with positive screening tests moved out of the country before evaluation could be completed. ${ }^{78}$ Caregiver refusal also acted as a barrier to completion of evaluation: a study of school-based screening in Canada found that of 724 paediatric patients with positive screening tests, $6 \%$ of patients/families 'refused' to visit a TB clinic for medical evaluation. ${ }^{40}$

No studies from LMIC documented reasons for noncompletion of medical evaluation. However, a study from Uganda noted that reliance on chest radiograph to exclude TB disease may not be feasible in many settings due to lack of radiography equipment. ${ }^{28}$ Using chest radiograph as a gold standard, authors devised a score based on cough and reduced playfulness that could identify child contacts with high probability of having TB disease, enabling them to differentiate these patients from paediatric patients with $\mathrm{TB}$ infection or no $\mathrm{TB}$ infection following exposure to infected adults.

\section{Step 5: completed medical evaluation $\rightarrow$ treatment recommended}

Thirty-nine studies documented completion of the fifth cascade step. Most studies documented high $(>90 \%)$ rates of recommendation to start treatment after completion of a medical examination. ${ }^{16} 283336-41434651535456575960656781-83$ 87-100 Only one study documented $<90 \%$ recommendation rate: a study from Australia in which $86 \%$ of paediatric patients with TB infection were recommended to start treatment. ${ }^{101}$ The primary reason treatment was not recommended in high-income countries and LMIC was because providing treatment was not strictly indicated, for example, because of guidelines not supporting TB infection treatment for select patients with positive tests ${ }^{3787}$ and presumed falsepositive tests in the setting of prior BCG vaccination. ${ }^{94}$

Clinicians' concerns about patients' medical state and ability to adhere to medication were identified as reasons for not recommending treatment in LMIC. Medical reasons for deferring to recommend treatment included concurrent chronic infections in children in India ${ }^{102}$ and elevated transaminases and medical instability in exposed neonates in South Korea. ${ }^{38}$ In high-income countries, behaviour concerns precluded treatment recommendation. In a study of unaccompanied asylum seekers in Sweden, treatment was not recommended for some patients who were felt to be 'psychologically unfit for treatment'. ${ }^{103}$ In this study, concerns about adherence arose from both perceived structural factors, such as likelihood of migrating out of catchment areas or becoming physically incarcerated or detained, and perceived psychological barriers to taking medication. ${ }^{103}$ No studies described interventions to improve retention at this step of the cascade.

\section{Step 6: treatment recommended $\rightarrow$ treatment started}

Forty-seven studies documented completion of the sixth cascade step. Rates of treatment initiation among patients for whom treatment was recommended ranged from $33 \%$ in a school-based contact investigation in the $\mathrm{USA}^{95}$ to $100 \%$ in several studies. ${ }^{2837-3941465153547487-89929496100}$

In both high-income countries and LMICs, patient or caregiver refusal was a major barrier to treatment initiation. ${ }^{1733364046596068819093959799102104}$ Several studies have examined reasons for treatment acceptance and refusal. Patient and caregiver concerns about medication adverse effects were a common cause of treatment refusal. ${ }^{51}{ }^{104} \mathrm{In}$ addition, a study of adolescent student contacts in China assessed associations with accepting treatment and found that students with a higher level of knowledge about TB (measured by a knowledge and attitudes survey) and close contact with a TB patient were more likely to accept treatment. ${ }^{104}$

Patient demographic characteristics have been linked to treatment refusal in high-income countries. ${ }^{40} 6499$ A report of a TB infection screening in largely immigrant classrooms in Canada found that immigrants from Eastern Europe had higher odds of treatment refusal (compared with immigrants from Southeast Asia, adjusted OR (aOR) 6.91 (95\% CI 1.56 to 30.75$)$ ), as did children living with one parent and a parent in law (a 'blended family', compared with non-'blended families') (aOR 3.25 (95\% CI 1.25 to 8.46)).$^{40}$ One study of paediatric patients with TB infection referred to a US paediatric hospital found that patients born in Pacific Asia, Eastern Europe, and North Africa and the Middle East had treatment refusal rates $>10 \%$, compared with $<10 \%$ among patients born in other regions, though statistical comparison was not performed. ${ }^{99}$ Among immigrants and refugees documented in the US Centers for Disease Control and Prevention (CDC) Electronic Disease Notification System, treatment initiation was 'slightly greater' in child refugees than child non-refugee immigrants. ${ }^{64}$

In studies from high-income countries, movement of patients was also linked to non-initiation of treatment. Two contact investigations in the USA noted that movement of patients out of clinical catchment areas and between care providers hindered documentation of treatment initiation. ${ }^{83}{ }^{95}$ We did not identify studies from high-income countries or LMICs that tested strategies to improve treatment initiation after recommendation.

\section{Step 7: treatment started $\rightarrow$ treatment completed}

Most articles identified in our scoping review described treatment adherence or completion. Most studies were retrospective and single site, although some prospectively sought to assess interventions to improve treatment 
adherence, either through shorter courses of treatment or dedicated adherence promotion programmes.

\section{Type and duration of treatment}

Two reviews concluded that shorter duration TB infection treatment regimens (4 months of rifampin, ${ }^{105}$ 3 months of rifampin and isoniazid ${ }^{105106}$ and 3 months of isoniazid and rifapentine via directly observed preventive treatment (DOPT) for paediatric patients over 2 years old $^{105}$ yield higher rates of completion than longer treatment regimens. The WHO has endorsed shorter duration rifamycin-based treatment regimens for children and adolescents $<15$ years old. ${ }^{22}$

Few studies in our review examined adherence to regimens tailored to multidrug-resistant (MDR) TB infection. A contact investigation in the Federated States of Micronesia found that 42 of 43 paediatric patients completed 12 months of fluoroquinolone-based treatment. ${ }^{107}$ In contrast, three studies from high-income countries demonstrated high rates of treatment changes or discontinuation to a variety of medications due to adverse medication effects. ${ }^{36} 108109$

Several studies from both high-income countries $^{329099110111}$ and LMICs ${ }^{29} 30112$ examined the timing of treatment discontinuation. These studies primarily evaluated 6 months or 9 months of isoniazid and used clinic return visits as a marker of adherence. Of patients who discontinued treatment, most stopped within the first 4 months.

\section{Treatment delivery strategy}

The most widely reported treatment delivery method in both high-income countries and LMICs was selfadministered treatment (SAT) with isoniazid, prescribed at public health department ${ }^{14165194102113-117}$ or TB/ infectious diseases/chest clinics. ${ }^{31} 408390111$ 118-126 DOPT was also frequently employed and universally used when patients were prescribed isoniazid plus rifapentine. ${ }^{3567127128}$ Apart from treatment-specific use of DOPT, other indications for DOPT were inconsistent across studies, with some reserving DOPT for young patients ${ }^{118}$ or those perceived to be at high risk for, or have proven, non-adherence. ${ }^{94} 125129$

Two studies from the US directly compared treatment delivery strategies. The first compared health departmentprescribed SAT with school-based DOPT, finding that SAT was associated with significantly lower rates of treatment completion compared with DOPT ( $50 \%$ vs $88 \%) .{ }^{85}$ The second found that receipt of 9 months of isoniazid or 6 months of rifampin via DOPT administered at a health department was associated with increased odds of treatment completion compared with SAT (aOR 7.2 9(95\% CI 5.7 to 23.6$)) .{ }^{90}$ In this study, DOPT was used for infants, young children, recent immigrants and patients receiving treatment as part of contact investigations, while older paediatric patients not in one of these categories were eligible for SAT.
Four studies from high-income countries described TB infection treatment adherence among patients initially evaluated at public health clinics but who could then be followed by primary paediatricians. ${ }^{8395108130}$ These studies did not attempt to analyse benefits and downsides of joint management models. While most programmes required monthly clinic return to refill prescriptions, a programme evaluation study in the USA described effects of enabling public health nurses to perform once monthly home visits for patients of all ages receiving $\mathrm{TB}$ infection treatment to ameliorate transportation-related loss to follow-up. ${ }^{131}$ Home follow-up was found to be associated with improved adherence among all patients (aOR $2.94,95 \%$ CI 2.23 to 3.71 ), although pediatric-specific ORs were not reported.

\section{Barriers and facilitators of treatment completion}

Many studies evaluated predictors of treatment completion among paediatric patients. Concerns about and experiences of medication adverse effects prevented treatment completion in both high-income countries and LMICs. ${ }^{17} 19313536568283102$ 107-109118 120121125126 132-135 Likewise, medical contraindications to treatment that occurred during treatment courses, such as pregnancy or intercurrent non-TB infections, occasionally prompted discontinuation. ${ }^{51} 8393107133$ In studies from LMIC, additional factors associated with treatment completion included caregiver education ${ }^{56}$ and knowledge about TB infection, ${ }^{81}$ personal health knowledge and beliefs, ${ }^{5681136}$ lack of stigma ${ }^{56}$ and close relationships with TB contacts. ${ }^{112}$

Studies from high-income countries have assessed patient and family characteristics associated with treatment completion. Identified factors associated with treatment completion include both younger age $^{131840688299116125137138}$ and older age, ${ }^{88}$ female sex, ${ }^{31}$ race/ethnicity, ${ }_{116} 138$ family composition ${ }^{40} 51 \quad 113$ and origin, ${ }^{40} 99115124$ supportive family and home environments ${ }^{125} 139$ and school achievement. ${ }^{137} 139$ Meanwhile, patient/family movement away from catchment areas could interrupt treatment. ${ }^{68} 8390100101118124$ Finally, knowledge and practice-related factors, including lack of caregiver knowledge about TB infection, confusion about treatment regimens and forgetfulness, were found to contribute to treatment discontinuation. ${ }^{51} 126135$

We included two mixed-methods or qualitative studies that assessed reasons for treatment non-adherence or non-completion. A survey study examined barriers to TB infection adherence among US adolescents enrolled in a peer-counselling and caregiver-training intervention. ${ }^{135}$ Barriers to treatment adherence existed for patients (lack of knowledge, missed visits, challenges with completing baseline TB infection evaluation and concern about side effects), caregivers (lack of knowledge, work conflicts, cost and concerns about side effects) and providers (lack of knowledge and resistance to recommendations). Research in Brazil found that lower monthly income, lower knowledge about $\mathrm{TB}$ transmission and BCG 
protection and higher cost of transportation were independently associated with non-adherence at 2 months. ${ }^{81}$

Studies from high-income countries investigated health systems factors that facilitated or impeded adherence and treatment completion, including treatment location, history of receiving care at the relevant clinic and prescriber type. Two studies demonstrated that delays in diagnostic steps prior to treatment initiation were associated with decreased treatment completion. ${ }^{40} 82$ Treatment setting and services also could affect completion, although locations and effects were heterogeneous. ${ }^{99} 108$ Establishing longitudinal care within a clinic or health system was associated with treatment completion. For example, a study of TB infection treatment in a US community health centre found higher treatment completion rates among paediatric patients who had attended $\geq 2$ well child checks at the clinic prior to treatment initiation. ${ }^{82}$ Two studies from Canada showed opposite effects of provider type on treatment completion, with one showing decreased odds of treatment completion when prescribers were primary care physicians, ${ }^{32}$ while the other found no difference in completion rates based on provider type. ${ }^{140}$

\section{Behavioural strategies to optimise adherence and treatment completion}

A prior review of reviews of IPT adherence promotion methods identified two reviews that included studies with paediatric patients, and each review included only a single study with children and adolescents. ${ }^{141}$ The authors concluded there was little evidence supporting effectiveness of specific paediatric TPT adherence promotion strategies, although integration of TB and HIV services might improve adherence.

We identified three trials of behavioural interventions targeting adolescents with TB infection, all of which took place in high-income countries. ${ }^{116} 139142$ None of these trials demonstrated improvement in adherence or treatment completion, although some secondary outcomes were met. A trial to improve TB infection treatment adherence among adolescents receiving care at two US public health clinics randomised patients to one of four behavioural interventions: counselling from peers who had completed TB infection treatment, a negotiated caregiver-participant 'contingency contract' using incentives provided by caregivers as reward for adherence, both peer counselling and contingency contracting, or usual care. ${ }^{116}$ There was no significant difference in completion rates between arms, though a secondary analysis indicated that peer counselling was positively associated with three mediating variables on the path to treatment completion: medication-taking behaviour, perceived mastery and perceived self-efficacy $(p<0.05$ for all scales). ${ }^{113115116}$ Another trial, based on the Behavioral Ecological Model, randomised US adolescents to adherence coaching, self-esteem counselling or usual care. The study found that adolescents randomised to adherence coaching took more pills (via monthly self-report) than patients in the other two arms, although rates of treatment completion were low $(38 \%-51 \%)$ and not different between groups. ${ }^{142}$ Finally, a follow-up trial in the USA assessed adherence peer counselling versus life skills peer counselling to optimise adherence (measured by self-reported isoniazid adherence, validated by urine metabolite detection) among adolescents. ${ }^{139}$ Treatment completion rates were low $(37 \%-40 \%)$, and there was no significant difference in treatment completion between the two study arms, although in a secondary multivariable analysis, total time spent in counselling sessions was associated with pill taking.

We identified two interventional studies that targeted adherence behaviours in children, both from highincome countries. One study described a rewards-based structural behavioural intervention administered at a US department of health clinic, in which young children were given a toy for completing treatment each month. ${ }^{143}$ This system was associated with increased odds of treatment completion compared with a historical cohort who did not receive incentives (aOR 2.42 (95\% CI 1.66 to $3.51)$ ). The second study compared 6-month or 9-month isoniazid treatment completion between patients of all ages, including children. ${ }^{131}$ Those patients deemed at high risk of treatment discontinuation were selected to receive monthly home nursing follow-up, while the remainder were followed monthly in clinic. Treatment completion rates were higher among patients assigned to home nursing follow-up across all groups $(95.7 \%$ vs $92.1 \%$ for children $<6$ years old, and $93.1 \%$ vs $84.1 \%$ for patients aged $6-17$ years old).

Additional interventions have been implemented to improve adherence among children and adolescents in high-income countries and LMICs, but effectiveness was not assessed against a control group. These include use of telemedicine DOPT,${ }^{127}$ provision of free medications, ${ }^{119}$ adherence counselling, ${ }^{31}$ small cash incentives ${ }^{107}$ and multimodal interventions that adjust treatment regimens and delivery strategies to patients' needs and attempt to individually address social/structural barriers to adherence. $^{88125}$

\section{DISCUSSION}

We identified a large literature describing steps of the TB infection care cascade for paediatric patients. Three key themes relating to the state of this literature are apparent from our review. First, most studies focused on the final cascade step: initiation to completion of treatment. Comparatively, little research has addressed steps leading to treatment initiation, despite evidence that up to $70 \%$ of patients who could benefit from TB infection treatment never start medication. ${ }^{3}$ Second, while studies identified heterogeneous factors associated with attrition from different cascade steps, identified factors were primarily related to patient/family characteristics. Few studies sought to identify health systems-related factors associated with cascade completion. Third, while 
a number of studies have described behavioural interventions to improve retention, data supporting the efficacy of these interventions are scant.

While studies have identified facilitators and barriers to completion of the initial six steps of the TB infection care cascade, identified barriers vary between steps and study sites. Many studies described non-specific loss to follow-up as a primary reason for attrition. Qualitative and mixed methods analyses have been used to understand loss to follow-up among persons living with $\mathrm{HIV}^{144}$ and could help to examine loss to follow-up among children and adolescents evaluated and treated for TB infection. We identified only one comparative efficacy trial targeting a step prior to treatment initiation, which showed qualified support for strategies to improve return after TST placement in a high-resource setting. ${ }^{71}$

Research from both high-resource and resourcelimited settings has extensively investigated barriers and facilitators of treatment adherence and completion (step 7). Robust data demonstrate tolerability and improved completion rates with shorter courses of rifamycin-based treatment, compared with 6-month or 9-month isoniazid regimens. ${ }^{143435105106120126140145146}$ In response to these data, both the WHO and the US CDC now recommend short-course treatments for TB infection. ${ }^{22} 105$ Trials of specific behavioural strategies to promote treatment adherence and completion have been less successful. Several key knowledge gaps remain to improve retention in the final step of the cascade, including: the scalability of promising pilot interventions; effects of specialist versus paediatric primary care teams ${ }^{32}$; potential for mobile health technologies (mHealth) to optimise adherence $^{127}$; utility of targeting interventions towards paediatric patients, caregivers or both; and specific barriers and facilitators of adherence in resource-limited settings.

In our review, identified system-level factors included type of care setting, provider type, clinical wait times, availability of interpreters and other clinical support staff, availability of testing and treatment, and time and financial cost of diagnosis and treatment. Published studies described contradictory conclusions about the direction of some of these factors' effects. For example, in studies examining the role of primary care providers and specialists in ensuring adherence to TB infection treatment, patients who receive prescriptions from generalists were more likely, ${ }^{99}$ equally likely ${ }^{140}$ or less likely ${ }^{32}$ to complete treatment than patients receiving treatment from specialists. One limitation of this literature is the reliance on data from single (mostly specialty) clinical settings, despite the fact that patients may transition between care settings for different steps of the care cascade. Research is needed to identify how to retain children and adolescents as they transition between community clinics, hospitals, specialty clinics, health department clinics and other care settings while navigating the cascade.

Few studies in our review assessed cascade completion among children and adolescents living with HIV, and we did not identify specific barriers or facilitators to these patients' retention in the care cascade. Notably, per WHO and country-specific guidance, children and adolescents living with HIV exposed to TB are not uniformly tested for TB infection prior to initiation of TPT, ${ }^{22}$ and studies reporting on these children may have been excluded from our review. In analyses that included adults with HIV, people living with HIV have been found to have higher rates of treatment completion than comparison groups. ${ }^{19} 20$

Children and adolescents in LMIC face unique barriers to retention in the care cascade. There remains a wide policy-practice gap in identifying those at high risk for TB disease and with TB infection, and active contact tracing and case finding in LMIC remain critical areas for improvement. ${ }^{147}$ Additionally, a limited supply of TB infection tests hampers efforts to diagnose high-risk children and adolescents. ${ }^{61} 74148$ Strategies to reduce cost and increase access to TST and IGRA in LMIC are needed to identify children and adolescents who would most benefit from TPT, including those not identified through contact tracing.

A sizeable body of research has investigated TPT adherence in LMIC administered as part of contact management. Although our review identified considerable literature on treatment completion, our requirement for TB infection testing inherently omitted several papers on TPT from LMIC in which infection testing was not done, per WHO guidelines. ${ }^{22}$ Drawing from literature excluded from our study, the prior review of contact case management in high-burden countries identified several barriers to completion of child contact management that overlap with our findings, including barriers posed by health systems, knowledge and attitudes, stigma, resource constraints, and treatment characteristics and adverse effects. ${ }^{23}$ To highlight valuable explanatory research on TPT from LMIC included in that prior review and published subsequently, qualitative and mixed-methods studies have illustrated how (lack of) knowledge, ${ }^{149-152}$ stigma, ${ }^{152-154}$ patient/caregiver and health system resource constraints, ${ }^{151} 152$ and combinations of these factors ${ }^{155}$ conspire to impede TPT initiation and completion in LMIC.

Several large, ongoing studies and programmes seek to scale interventions to improve cascade retention in LMIC. Examples include projects to increase rifapentine access for people living with HIV and child contacts $<5$ years old ${ }^{156}$; that test and scale novel approaches to $\mathrm{TB}$ diagnostics and retention in care ${ }^{157}$; and that use the TB infection care cascade as a framework to identify stepspecific, locally tailored interventions to improve retention. ${ }^{42} 43158$ Additional studies to improve TPT initiation among child contacts in LMIC have shown promising results of socioeconomic support, ${ }^{148}$ enhanced contact investigation procedures ${ }^{48}$ and multilevel community interventions. ${ }^{159}$

Our analysis suggests several theory-based and methodological strategies to strengthen future research and programme implementation to improve retention 
in the TB infection care cascade. First, behavioural theory can help structure intervention design and evaluation. In our review, there was sporadic use of established behavioural theories in building interventions to improve the cascade, and theory was only employed to understand and modify the final cascade step. ${ }^{115} 116142143$ Application of behavioural and organisational theory to upstream cascade steps is needed. For instance, behavioural theories may yield insights and testable solutions to caregivers' refusal of TB infection testing for their children. Implementation science theory, models and frameworks may also prove useful in addressing barriers for a number of steps, such as improving health systems to mitigate loss to follow-up during transitions of care. Additionally, although recent literature has increasingly used quality improvement methods to address TB infection care,${ }^{25} 160$ we did not identify any studies that used these methods to iteratively test and improve interventions.

Our review has several limitations. First, we did not attempt to survey the extensive literature on patients who received TPT following contact with individuals with infectious TB but who were not tested for TB infection. Despite the extensive research we identified describing the final cascade step, this research mostly took place in high-resource settings. Additional research from LMIC on supporting child contacts undergoing TPT who were not tested for TB infection has been summarised in detail in the prior case management review, ${ }^{23}$ though expanding testing capacity in LMIC remains a critical gap. Second, while broad, our search strategy may not have captured all pertinent literature on the cascade. Likewise, our language restrictions may have excluded relevant studies. Third, we did not perform a quality assessment of articles because of the heterogeneity of study types and because we chose to focus on exploring all insights the literature had to offer, as is common in scoping reviews. ${ }^{27}$ Fourth, a single reviewer assessed all studies, although any points of ambiguity were discussed among all authors. Finally, while the care cascade we used provides a useful framework to understand processes for diagnosing and treating $\mathrm{TB}$ infection, there is heterogeneity in local and international TB infection treatment guidance and practice, and not all steps are used in all settings. Our study also has several strengths. We identified studies from a range of geographic and care delivery settings, describing a variety of paediatric populations. We also identified studies that included unique populations, such as paediatric patients with MDR TB infection, infants, adolescents and refugees/asylum seekers.

In conclusion, our scoping review identified key gaps in understanding the paediatric TB infection care cascade. Future research should target knowledge gaps in the early steps of the cascade and identify modifiable health systems factors associated with cascade attrition. Future interventions should aim to be sustainable, theorygrounded, iteratively optimised and locally relevant.
Acknowledgements We would like to thank Chloe Rotman for her assistance with designing the literature search strategy. We would also like to thank the anonymous reviewers, whose comments and suggestions greatly strengthened the paper.

Contributors JC conceived of the study; gathered data; synthesised, analysed and interpreted data; and drafted the manuscript. TJS and JH conceived of the study; synthesised and interpreted data; and critically revised the manuscript. All authors approved the final version of the manuscript for publication. All authors agree to be accountable for all aspects of the work.

Funding JC was supported by AHRQ grant number T32HS000063 as part of the Harvard-wide Paediatric Health Services Research Fellowship Programme. JH was supported by the National Institute of Mental Health (K24MH114732).

Competing interests None declared.

Patient consent for publication Not required.

Provenance and peer review Not commissioned; externally peer reviewed.

Data availability statement Data are available on request. Data are available from the authors on request.

Supplemental material This content has been supplied by the author(s). It has not been vetted by BMJ Publishing Group Limited (BMJ) and may not have been peer-reviewed. Any opinions or recommendations discussed are solely those of the author(s) and are not endorsed by BMJ. BMJ disclaims all liability and responsibility arising from any reliance placed on the content. Where the content includes any translated material, BMJ does not warrant the accuracy and reliability of the translations (including but not limited to local regulations, clinical guidelines, terminology, drug names and drug dosages), and is not responsible for any error and/or omissions arising from translation and adaptation or otherwise.

Open access This is an open access article distributed in accordance with the Creative Commons Attribution Non Commercial (CC BY-NC 4.0) license, which permits others to distribute, remix, adapt, build upon this work non-commercially, and license their derivative works on different terms, provided the original work is properly cited, appropriate credit is given, any changes made indicated, and the use is non-commercial. See: http://creativecommons.org/licenses/by-nc/4.0/.

\section{REFERENCES}

1 WHO. Implementing the end TB strategy: the essentials. WHO Press, 2015.

2 WHO. Global tuberculosis report 2020. WHO Press, 2020.

3 Alsdurf $\mathrm{H}$, Hill PC, Matteelli A. The cascade of care in diagnosis and treatment of latent tuberculosis infection: a systematic review and meta-analysis. Lancet Infect Dis 2016;16:1269-78.

4 Bock NN, Metzger BS, Tapia JR, et al. A tuberculin screening and isoniazid preventive therapy program in an inner-city population. Am J Respir Crit Care Med 1999;159:295-300.

5 Bonvicini F, Cilloni S, Fornaciari R, et al. Compliance with tuberculosis screening in irregular immigrants. Int J Environ Res Public Health 2018;16. doi:10.3390/ijerph16010028. [Epub ahead of print: 23 Dec 2018].

6 Rennert-May E, Hansen E, Zadeh T, et al. A step toward tuberculosis elimination in a low-incidence country: successful diagnosis and treatment of latent tuberculosis infection in a refugee clinic. Can Respir J 2016;2016:1-6.

7 Pontarelli A, Marchese V, Scolari C, et al. Screening for active and latent tuberculosis among asylum seekers in Italy: a retrospective cohort analysis. Travel Med Infect Dis 2019;27:39-45.

8 Pease C, Zwerling A, Mallick R, et al. The latent tuberculosis infection cascade of care in lqaluit, Nunavut, 2012-2016. BMC Infect Dis 2019;19:1-10.

9 Mugisha B, Bock N, Mermin J, et al. Tuberculosis case finding and preventive therapy in an HIV voluntary counseling and testing center in Uganda. Int J Tuberc Lung Dis 2006;10:761-7.

10 Marks SM, Taylor Z, Qualls NL, et al. Outcomes of contact investigations of infectious tuberculosis patients. Am J Respir Crit Care Med 2000;162:2033-8.

11 Flynn MG, Brown LK. Treatment of latent tuberculosis in migrants to Victoria. Commun Dis Intell Q Rep 2015;39:E578-83.

12 Chang LW, Njie-Carr V, Kalenge S, et al. Perceptions and acceptability of mHealth interventions for improving patient care at a community-based HIV/AIDS clinic in Uganda: a mixed methods study. AIDS Care 2013;25:874-80. 
13 Bieberly J, Ali J. Treatment adherence of the latently infected tuberculosis population (post-Katrina) at Wetmore TB clinic, new Orleans, USA. Int J Tuberc Lung Dis 2008;12:1134-8.

$14 \mathrm{Li} \mathrm{J}$, Munsiff SS, Tarantino T, et al. Adherence to treatment of latent tuberculosis infection in a clinical population in New York City. Int $J$ Infect Dis 2010;14:e292-7.

15 Milinkovic DA, Birch S, Scott F. A cohort study of factors associated with LTBI treatment initiation and completion in Hamilton, Ontario, Canada. Can J Infect Cont 2018;33:82-8.

16 Nuzzo JB, Golub JE, Chaulk P, et al. Analysis of latent tuberculosis infection treatment adherence among refugees and other patient groups referred to the Baltimore City health department TB clinic, February 2009-March 2011. J Immigr Minor Health 2015;17:56-65.

17 Sandul AL, Nwana N, Holcombe JM, et al. High rate of treatment completion in program settings with 12-Dose Weekly isoniazid and rifapentine for latent Mycobacterium tuberculosis infection. Clin Infect Dis 2017;65:1085-93.

18 Saunders MJ, Koh GCKW, Small AD, et al. Predictors of contact tracing completion and outcomes in tuberculosis: a 21-year retrospective cohort study. Int J Tuberc Lung Dis 2014;18:640-6.

19 Séraphin MN, Hsu H, Chapman HJ, et al. Timing of treatment interruption among latently infected tuberculosis cases treated with a nine-month course of daily isoniazid: findings from a time to event analysis. BMC Public Health 2019;19:1214.

20 Stockbridge EL, Miller TL, Carlson EK, et al. Predictors of latent tuberculosis infection treatment completion in the US private sector: an analysis of administrative claims data. BMC Public Health 2018;18:662.

21 Hirsch-Moverman Y, Daftary A, Franks J, et al. Adherence to treatment for latent tuberculosis infection: systematic review of studies in the US and Canada. Int J Tuberc Lung Dis 2008;12:1235-54.

22 WHO. WHO consolidated guidelines on tuberculosos. Module 1: prevention - tuberculosis preventive treatment. WHO press, 2020

23 Szkwarko D, Hirsch-Moverman Y, Du Plessis L, et al. Child contact management in high tuberculosis burden countries: a mixedmethods systematic review. PLoS One 2017;12:e0182185.

24 WHO. WHO operational handbook on tuberculosis. Module 1: prevention - tuberculosis preventive treatment. WHO press, 2020.

25 Hannah A, Dick M. Identifying gaps in the quality of latent tuberculosis infection care. J Clin Tuberc Other Mycobact Dis 2020;18:100142.

26 Tricco AC, Lillie E, Zarin W, et al. PRISMA extension for scoping reviews (PRISMA-ScR): checklist and explanation. Ann Intern Med 2018;169:467-73.

27 Pham MT, Rajić A, Greig JD, et al. A scoping review of scoping reviews: advancing the approach and enhancing the consistency. Res Synth Methods 2014;5:371-85.

28 Bonnet M, Kyakwera C, Kyomugasho N, et al. Prospective cohort study of the feasibility and yield of household child tuberculosis contact screening in Uganda. Int J Tuberc Lung Dis 2017;21:862-8.

29 Gomes VF, Wejse C, Oliveira I, et al. Adherence to isoniazid preventive therapy in children exposed to tuberculosis: a prospective study from Guinea-Bissau. int $j$ tuberc lung dis 2011;15:1637-43.

30 Mendonça AMC, Kritski AL, Land MGP, et al. Abandonment of treatment for latent tuberculosis infection and socioeconomic factors in children and adolescents: Rio de Janeiro, Brazil. PLoS One 2016;11:e0154843.

31 Rogo T, Eleanya C, Hirway P, et al. Adherence to latent tuberculosis infection treatment in a population with a high number of refugee children. R I Med J 2017;100:34-8.

32 Rubinowicz A, Bartlett G, MacGibbon B, et al. Evaluating the role of primary care physicians in the treatment of latent tuberculosis: a population study. Int J Tuberc Lung Dis 2014;18:1449-54.

33 Said K, Hella J, Ruzegea M, et al. Immunologic-based diagnosis of latent tuberculosis among children younger than 5 years of age exposed and unexposed to tuberculosis in Tanzania. Pediatr Infect Dis J 2019;38:333-9.

34 van Zyl S, Marais BJ, Hesseling AC, et al. Adherence to antituberculosis chemoprophylaxis and treatment in children. Int $J$ Tuberc Lung Dis 2006;10:13-18.

35 Villarino ME, Scott NA, Weis SE, et al. Treatment for preventing tuberculosis in children and adolescents: a randomized clinical trial of a 3-month, 12-dose regimen of a combination of rifapentine and isoniazid. JAMA Pediatr 2015;169:247-55.

36 Adler-Shohet FC, Low J, Carson M, et al. Management of latent tuberculosis infection in child contacts of multidrug-resistant tuberculosis. Pediatr Infect Dis J 2014;33:664-6.

37 Ahmad BB, Kristensen KL, Glenthoej JP, et al. Latent tuberculosis infection among minor asylum seekers in Denmark. Eur Respir J
2020;55. doi:10.1183/13993003.01688-2019. [Epub ahead of print: $09012020]$.

38 Ahn JG, Kim DS, Kim KH. Nosocomial exposure to active pulmonary tuberculosis in a neonatal intensive care unit. $\mathrm{Am} \mathrm{J}$ Infect Control 2015;43:1292-5.

39 Hatzenbuehler LA, Starke JR, Graviss EA, et al. School-based study to identify and treat adolescent students at risk for tuberculosis infection. Pediatr Infect Dis J 2016;35:733-8.

40 Minodier P, Lamarre V, Carle M-E, et al. Evaluation of a school-based program for diagnosis and treatment of latent tuberculosis infection in immigrant children. $J$ Infect Public Health 2010;3:67-75.

41 Parvaresh L, Bag SK, Cho J-G, et al. Monitoring tuberculosis contact tracing outcomes in Western Sydney, Australia. BMJ Open Respir Res 2018;5:e000341.

42 Oxlade O, Trajman A, Benedetti A, et al. Enhancing the public health impact of latent tuberculosis infection diagnosis and treatment (ACT4): protocol for a cluster randomised trial. BMJ Open 2019;9:e025831.

43 Barss L, Obeng J, Fregonese F, et al. Solutions to improve the latent tuberculosis cascade of care in Ghana: a longitudinal impact assessment. BMC Infect Dis 2020;20:352.

44 Aldeco M, Praprotnik M, Mramor M. Contact investigation in management of newborns after exposure to Mycobacterium tuberculosis from a health care worker. European Respiratory Journal 2011;38.

45 Hwang WJ, Lee GU, Kim SH, et al. Childhood tuberculosis contact investigation and treatment of latent tuberculosis infection: a single center study, 2014-2017. Pediatr Infect Vaccine 2019;26:32-41.

46 Berlioz M, Del Mar Corcostegui M, Dalfin M, et al. [Experience of extensive screening of Mycobacterium tuberculosis transmission to patients exposed to a pediatrician]. Arch Pediatr 2008;15:1637-42.

47 Wysocki AD, Villa TCS, Arakawa T, et al. Latent tuberculosis infection diagnostic and treatment cascade among contacts in primary health care in a city of Sao Paulo state, Brazil: crosssectional study. PLoS One 2016;11:e0155348.

48 Sulis G, Combary A, Getahun H, et al. Implementation of tuberculosis prevention for exposed children, Burkina Faso. Bull World Health Organ 2018;96:386-92.

49 Huerga H, Sanchez-Padilla E, Melikyan N, et al. High prevalence of infection and low incidence of disease in child contacts of patients with drug-resistant tuberculosis: a prospective cohort study. Arch Dis Child 2019;104:622-8.

50 Baliashvili D, Kempker RR, Blumberg HM, et al. A population-based tuberculosis contact investigation in the country of Georgia. Public Health Action 2018;8:110-7.

51 Brassard P, Lamarre V. Evaluation of Mycobacterium tuberculosis transmission from a pediatrician and initial compliance to prophylaxis of contacts in an outpatient pediatric clinic. Pediatr Infect Dis J 2000;19:968-72.

52 Bedoya DB, Arbeláez Montoya MP. Study and clinical management of child household contacts of tuberculosis patients, medellin 2010-2011. latreia 2015;28:137-47.

$53 \mathrm{Kim}$ Y, Kim BK, Choi HJ, et al. Lessons learned from continued TB outbreaks in a high school. PLoS One 2017;12:e0188076.

54 Müller LL, Bennet R, Gaines H, et al. Complexity in estimating recent tuberculosis transmission among predominantly immigrant school children in Stockholm, Sweden 2006. Scand J Infect Dis 2008:40:709-14.

55 Anaraki S, Bell AJ, Perkins S, et al. Expected background rates of latent TB infection in London inner City schools: lessons from a TB contact investigation exercise in a secondary school. Epidemiol Infect 2018;146:2102-6.

56 Huang $\mathrm{H}$, Yuan G, Du Y, et al. Effects of preventive therapy for latent tuberculosis infection and factors associated with treatment abandonment: a cross-sectional study. J Thorac Dis 2018;10:4377-86

57 Calder L, Rivers J, Hayhurst M, et al. A school and community outbreak of tuberculosis in Palmerston North, New Zealand. N Z Med J 2008;121:50-61.

58 Wang S-H, Hunt WG, Powell DA. Lessons learned from two school tuberculosis investigations. J Immigr Minor Health 2010;12:853-8.

59 Phillips L, Carlile J, Smith D. Epidemiology of a tuberculosis outbreak in a rural Missouri high school. Pediatrics 2004:113:e514-9.

60 Song S, Jeon D, Kim JW, et al. Performance of confirmatory interferon- $\gamma$ release assays in school TB outbreaks. Chest 2012:141:983-8.

61 Hosten E, Mehta M, Andre E, et al. Tuberculosis contact-tracing among Syrian refugee populations: lessons from Jordan. Confl Health 2018;12:25. 
62 Loutet MG, Burman M, Jayasekera N, et al. National roll-out of latent tuberculosis testing and treatment for new migrants in England: a retrospective evaluation in a high-incidence area. Eur Respir J 2018;51. doi:10.1183/13993003.01226-2017. [Epub ahead of print: 11 Jan 2018].

63 Herchline T, Trent A. 796. treatment of latent tuberculosis infection in a refugee population. Open Forum Infect Dis 2018;5:S286.

64 Taylor EM, Painter J, Posey DL, et al. Latent tuberculosis infection among immigrant and refugee children arriving in the United States: 2010. J Immigr Minor Health 2016;18:966-70.

65 Bibi H, Weiler-Ravell D, Shoseyov D, et al. Compliance to treatment of latent tuberculosis infection in a region of Israel. Isr Med Assoc J 2002;4:13-16.

66 Alavi SM, Sefidgaran GH. Tuberculin survey among school-aged children in Ahvaz, Iran, 2006. Int J Infect Dis 2008;12:406-9.

67 Wang $X$, Jiang $H$, Wang $X$, et al. ESMPE: a combined strategy for school tuberculosis prevention and control proposed by Dalian, China. PLoS One 2017;12:e0185646.

68 Brassard P, Steensma C, Cadieux L, et al. Evaluation of a schoolbased tuberculosis-screening program and associate investigation targeting recently immigrated children in a low-burden country. Pediatrics 2006;117:e148-56.

69 Sipan C, Blumberg E, Hovell M, et al. Screening Latino adolescents for latent tuberculosis infection (LTBI). Public Health Rep 2003:118:425-33.

70 van der Heijden YF, Heerman WJ, McFadden S, et al. Missed opportunities for tuberculosis screening in primary care. J Pediatr 2015;166:1240-5.

71 Cheng TL, Ottolini MC, Baumhaft K, et al. Strategies to increase adherence with tuberculosis test reading in a high-risk population. Pediatrics 1997;100:210-3.

72 Al Mekaini LA, Al Jabri ON, Narchi H, et al. The use of an interferongamma release assay to screen for pediatric latent tuberculosis infection in the eastern region of the Emirate of abu dhabi. Int $J$ Infect Dis 2014;23:4-7.

73 Rinsky JL, Farmer D, Dixon J, et al. Notes from the Field: Contact Investigation for an Infant with Congenital Tuberculosis Infection - North Carolina, 2016. MMWR Morb Mortal Wkly Rep 2018;67:670-1.

74 Coprada L, Yoshimatsu S, Querri A, et al. A review of tuberculosis contact investigations in the poor urban areas of Manila, the Philippines. Public Health Action 2016;6:220-5.

75 Khalid FA, Eldirdery MM, El-Gasim ME-O, et al. Tuberculin reactivity in schoolchildren, Kassala state, Sudan. Int J Mycobacteriol 2020;9:200-4.

76 Vivier PM, O'haire C, Alario AJ, et al. A statewide assessment of tuberculin skin testing of preschool children enrolled in Medicaid managed care. Matern Child Health J 2006;10:171-6.

77 Sloot R, Van Der Loeff MFS, Kouw PM. Yield of tuberculosis contact investigations in Amsterdam: opportunities for improvement. European Respiratory Journal 2014;44:714-24.

78 Usemann J, Ledergerber M, Fink G, et al. Cost-effectiveness of tuberculosis screening for migrant children in a low-incidence country. Int J Tuberc Lung Dis 2019;23:579-86.

79 Wong YJ, Lee SWH. Prevalence of latent tuberculosis among refugee children in Malaysia. ERJ Open Res 2020;6. doi:10.1183/23120541.00254-2019. [Epub ahead of print: 09 Mar 2020]

80 Christy C, Pulcino ML, Lanphear BP, et al. Screening for tuberculosis infection in urban children. Arch Pediatr Adolesc Med 1996;150:722-6.

81 Silva APB, Hill P, Belo MTCT, et al. Non-completion of latent tuberculous infection treatment among children in Rio de Janeiro state, Brazil. Int J Tuberc Lung Dis 2016;20:479-86.

82 Young J, Edick T, Klee D, et al. Successful treatment of pediatric latent tuberculosis infection in a community health center clinic. Pediatr Infect Dis J 2012;31:e147-51.

83 Chang S-H, Eitzman SR, Nahid P, et al. Factors associated with failure to complete isoniazid therapy for latent tuberculosis infection in children and adolescents. J Infect Public Health 2014;7:145-52.

84 George SA, Ko CA, Kirchner HL, et al. The role of chest radiographs and tuberculin skin tests in tuberculosis screening of internationally adopted children. Pediatr Infect Dis $J$ 2011;30:387-91.

85 Kohn MR, Arden MR, Vasilakis J, et al. Directly observed preventive therapy. Turning the tide against tuberculosis. Arch Pediatr Adolesc Med 1996;150:727-9.

86 Breuss E, Helbling P, Altpeter E, et al. Screening and treatment for latent tuberculosis infection among asylum seekers entering Switzerland. Swiss Med Wkly 2002;132:197-200.
87 Albanese SPR, da Costa AANF, Pieri FM, et al. Prevalence and evolution of Mycobacterium tuberculosis infection in tuberculosis case contacts. Rev Soc Bras Med Trop 2015;48:307-13.

88 Bishara $\mathrm{H}$, Ore L, Vinitsky $\mathrm{O}$, et al. Cost of nurse-managed latent tuberculous infection treatment among hard-to-reach immigrants in Israel. Int J Tuberc Lung Dis 2015;19:799-804.

89 Calzada-Hernández J, Anton-López J, Bou-Torrent R, et al. Tuberculosis in pediatric patients treated with anti-TNF $\alpha$ drugs: a cohort study. Pediatr Rheumatol Online J 2015;13:54.

90 Cruz AT, Starke JR. Increasing adherence for latent tuberculosis infection therapy with health department-administered therapy. Pediatr Infect Dis J 2012;31:193-5.

91 de Pontual L, Hollebecque V, Bessa Z, et al. Childhood tuberculosis in a low-income Paris suburb: lessons from a resurgence brought under control. Int J Tuberc Lung Dis 2004;8:976-81.

92 Dewan PK, Banouvong $\mathrm{H}$, Abernethy $\mathrm{N}$, et al. A tuberculosis outbreak in a private-home family child care center in San Francisco, 2002 to 2004. Pediatrics 2006;117:863-9.

93 Diallo T, Adjobimey M, Ruslami R, et al. Safety and side effects of rifampin versus isoniazid in children. $N$ Engl $\mathrm{J}$ Med 2018;379:454-63.

94 Elliot C, Marais B, Williams P, et al. Tuberculin skin test versus interferon-gamma release assay in refugee children: a retrospective cohort study. J Paediatr Child Health 2018;54:834-9.

95 Kaiser C, Cole B, Saruwatari K, et al. Rapid large-scale deployment of tuberculosis testing in a high school - Riverside County, California, 2013-2014. MMWR Morb Mortal Wkly Rep 2015;64:574-7.

96 Kondo S, Ito M. [Efficacy of tuberculosis contacts investigation and treatment, especially of preventive therapy in infants and young children]. Kekkaku 2003;78:677-82.

97 Korneva N, Starshinova A, Ananiev S. Risk of developing active TB in children with latent TB infection. Eur Resp J 2015;46.

98 Reichler MR, Reves R, Bur S, et al. Treatment of latent tuberculosis infection in contacts of new tuberculosis cases in the United States. South Med J 2002;95:414-20.

99 Spicer KB, Perkins L, DeJesus B, et al. Completion of latent tuberculosis therapy in children: impact of country of origin and neighborhood clinics. J Pediatric Infect Dis Soc 2013;2:312-9.

100 Thee S, Krüger R, von Bernuth $\mathrm{H}$, et al. Screening and treatment for tuberculosis in a cohort of unaccompanied minor refugees in Berlin, Germany. PLoS One 2019;14:e0216234.

101 Boyd R, Johnston V, Farmer B, et al. Treatment of latent tuberculosis infections in the Darwin region. Med $J$ Aust 2017;206:306-7.

102 Dorjee K, Topgyal S, Dorjee C, et al. High prevalence of active and latent tuberculosis in children and adolescents in Tibetan schools in India: the zero TB kids initiative in Tibetan refugee children. Clin Infect Dis 2019;69:760-8.

103 Bennet R, Eriksson M. Tuberculosis infection and disease in the 2015 cohort of unaccompanied minors seeking asylum in northern Stockholm, Sweden. Infect Dis 2017;49:501-6.

104 Li Y, Zheng YH, Lu LP, et al. Acceptance of Chemo-prophylaxis for latent tuberculosis infection among high School/College student contacts of tuberculosis patients in Shanghai, China. Biomed Environ Sci 2018;31:317-21.

105 Sterling TR, Njie G, Zenner D, et al. Guidelines for the treatment of latent tuberculosis infection: recommendations from the National tuberculosis controllers association and CDC, 2020. MMWR Recomm Rep 2020;69:1-11.

106 Assefa Y, Assefa Y, Woldeyohannes S, et al. 3-Month daily rifampicin and isoniazid compared to 6- or 9-month isoniazid for treating latent tuberculosis infection in children and adolescents less than 15 years of age: an updated systematic review. Eur Respir $J$ 2018;52. doi:10.1183/13993003.00395-2018. [Epub ahead of print: 11 Jul 2018].

107 Bamrah S, Brostrom R, Dorina F, et al. Treatment for LTBI in contacts of MDR-TB patients, Federated states of Micronesia 2009-2012. Int J Tuberc Lung Dis 2014;18:912-8.

108 Feja K, McNelley E, Tran CS, et al. Management of pediatric multidrug-resistant tuberculosis and latent tuberculosis infections in New York City from 1995 to 2003. Pediatr Infect Dis J 2008;27:907-12.

109 Cruz AT, Merchant O, Zafar A, et al. Tuberculosis exposure, infection and disease among children with medical comorbidities. Pediatr Infect Dis J 2014;33:885-8.

110 Horsburgh CR, Goldberg S, Bethel J, et al. Latent TB infection treatment acceptance and completion in the United States and Canada. Chest 2010;137:401-9. 
111 Parsyan AE, Saukkonen J, Barry MA, et al. Predictors of failure to complete treatment for latent tuberculosis infection. J Infect 2007;54:262-6.

112 Hamdi B, Blibech $\mathrm{H}$, Berraies A. Evaluation of adherence to tuberculosis screening in children. Eur Resp J 2016;48.

113 Coly A, Morisky D. Predicting completion of treatment among foreign-born adolescents treated for latent tuberculosis infection in Los Angeles. Int J Tuberc Lung Dis 2004;8:703-10.

114 Crossa A, Kessler J, Harris TG. Enhanced tuberculosis infection treatment outcomes after implementation of QuantiFERON $®$-Gold testing. PLoS One 2015;10:e0138349.

115 Kominski GF, Varon SF, Morisky DE, et al. Costs and costeffectiveness of adolescent compliance with treatment for latent tuberculosis infection: results from a randomized trial. $J$ Adolesc Health 2007:40:61-8.

116 Morisky DE, Malotte CK, Ebin V, et al. Behavioral interventions for the control of tuberculosis among adolescents. Public Health Rep 2001;116:568-74.

117 Page KR, Sifakis F, Montes de Oca R, et al. Improved adherence and less toxicity with rifampin vs isoniazid for treatment of latent tuberculosis: a retrospective study. Arch Intern Med 2006;166:1863-70.

118 Cruz AT, Starke JR. Safety and completion of a 4-month course of rifampicin for latent tuberculous infection in children. Int $J$ Tuberc Lung Dis 2014:18:1057-61.

119 Dobler CC, Marks GB. Completion of treatment for latent tuberculosis infection with monthly drug dispensation directly through the tuberculosis clinic. PLoS One 2012;7:e48900.

120 Gaensbauer J, Aiona K, Haas M, et al. Better completion of pediatric latent tuberculosis treatment using 4 months of rifampin in a US-based tuberculosis clinic. Pediatr Infect Dis $J$ 2018;37:224-8

121 Kwara A, Herold JS, Machan JT, et al. Factors associated with failure to complete isoniazid treatment for latent tuberculosis infection in Rhode island. Chest 2008;133:862-8.

122 Lardizabal A, Passannante M, Kojakali F, et al. Enhancement of treatment completion for latent tuberculosis infection with 4 months of rifampin. Chest 2006;130:1712-7.

123 Olsson $\mathrm{O}$, Winqvist $\mathrm{N}$, Olsson $\mathrm{M}$, et al. High rate of latent tuberculosis treatment completion in immigrants seeking asylum in Sweden. Infect Dis 2018;50:678-86.

124 Powell DA, Perkins L, Wang S-H, et al. Completion of therapy for latent tuberculosis in children of different nationalities. Pediatr Infect Dis J 2008;27:272-4.

125 Santos JC, Silva JB, Rangel MA, et al. Preventive therapy compliance in pediatric tuberculosis - A single center experience. Pulmonology 2020;26:78-83.

126 Spyridis NP, Spyridis PG, Gelesme A, et al. The effectiveness of a 9-month regimen of isoniazid alone versus 3- and 4-month regimens of isoniazid plus rifampin for treatment of latent tuberculosis infection in children: results of an 11-year randomized study. Clin Infect Dis 2007;45:715-22.

127 Donahue ML, Eberly M, Stagliano D, et al. 1367. Tele-TB: using telemedicine to increase access to directly observed therapy for latent tuberculosis infections. Open Forum Infect Dis 2019;6:S495.

128 Macaraig MM, Jalees M, Lam C, et al. Improved treatment completion with shorter treatment regimens for latent tuberculous infection. Int J Tuberc Lung Dis 2018;22:1344-9.

129 Guix-Comellas E-M, Rozas L, Velasco-Arnaiz E, et al. Adherence to antituberculosis drugs in children and adolescents in a lowendemic setting: a retrospective series. Pediatr Infect Dis $J$ 2017;36:616-8.

130 Souder E, Vodzak J, Long SS, et al. Public health department contact investigation and directly observed prophylactic therapy enhance completion of latent tuberculosis infection (LTBI) therapy in children compared with adults. Open Forum Infect Dis 2016;3.

131 Chang $\mathrm{AH}$, Polesky A, Bhatia $\mathrm{G}$. House calls by community health workers and public health nurses to improve adherence to isoniazid monotherapy for latent tuberculosis infection: a retrospective study. BMC Public Health 2013;13:894-94.

132 Cruz AT, Starke JR. Twice-weekly therapy for children with tuberculosis infection or exposure. Int $J$ Tuberc Lung Dis 2013;17:169-74.

133 Daskalaki I, Byun J, Dogbey MC, et al. Tolerability of rifampin monotherapy for latent tuberculosis infection in children. Pediatr Infect Dis J 2011;30:1014-5.

134 Erkens CGM, Slump E, Verhagen M, et al. Monitoring latent tuberculosis infection diagnosis and management in the Netherlands. Eur Respir J 2016;47:1492-501.

135 Hill L, Blumberg E, Sipan C, et al. Multi-Level barriers to LTBI treatment: a research note. J Immigr Minor Health 2010;12:544-50.
136 Li Y, Zhou C, Zheng Y, et al. The acceptability and feasibility of chemical prophylaxis for schoolchildren and adolescents with latent tuberculosis infection in Shanghai, China: a qualitative study. Int J Infect Dis 2016;45:397.

137 Hovell M, Blumberg E, Gil-Trejo L, et al. Predictors of adherence to treatment for latent tuberculosis infection in high-risk Latino adolescents: a behavioral epidemiological analysis. Soc Sci Med 2003;56:1789-96

138 Morisky DE, Ebin VJ, Malotte CK, et al. Assessment of tuberculosis treatment completion in an ethnically diverse population using two data sources. Implications for treatment interventions. Eval Health Prof 2003;26:43-58.

139 Hovell MF, Schmitz KE, Blumberg EJ, et al. Lessons learned from two interventions designed to increase adherence to LTBI treatment in Latino youth. Contemp Clin Trials Commun 2018;12:129-36.

140 Ronald LA, FitzGerald JM, Bartlett-Esquilant G, et al. Treatment with isoniazid or rifampin for latent tuberculosis infection: population-based study of hepatotoxicity, completion and costs. Eur Respir J 2020;55:1902048.

141 Adams LV, Talbot EA, Odato K, et al. Interventions to improve delivery of isoniazid preventive therapy: an overview of systematic reviews. BMC Infect Dis 2014;14.

142 Hovell MF, Sipan CL, Blumberg EJ, et al. Increasing Latino adolescents' adherence to treatment for latent tuberculosis infection: a controlled trial. Am J Public Health 2003;93:1871-7.

143 Cass AD, Talavera GA, Gresham LS, et al. Structured behavioral intervention to increase children's adherence to treatment for latent tuberculosis infection. Int J Tuberc Lung Dis 2005;9:415-20.

144 Mpinganjira S, Tchereni T, Gunda A, et al. Factors associated with loss-to-follow-up of HIV-positive mothers and their infants enrolled in HIV care clinic: a qualitative study. BMC Public Health 2020;20:298.

145 Plourde PJ, Basham CA, Derksen S, et al. Latent tuberculosis treatment completion rates from prescription drug administrative data. Can J Public Health 2019;110:705-13.

146 Venturini E, Tersigni C, Cordola C, et al. Latent tuberculosis treatment compliance in children: a 10-year experience. Pediatr Infect Dis J 2018;37:617.

147 WHO. Roadmap towards ending TB in children and adolescents, second edition. WHO Press, 2018.

148 Wingfield T, Tovar MA, Huff D, et al. A randomized controlled study of socioeconomic support to enhance tuberculosis prevention and treatment, Peru. Bull World Health Organ 2017;95:270-80.

149 Arscott-Mills T, Masole L, Ncube R, et al. Survey of health care worker knowledge about childhood tuberculosis in high-burden centers in Botswana. Int J Tuberc Lung Dis 2017;21:586-91.

150 Banu Rekha VV, Jagarajamma K, Wares F, et al. Contact screening and chemoprophylaxis in India's revised tuberculosis control programme: a situational analysis. Int $J$ Tuberc Lung Dis 2009;13:1507-12

151 Singh AR, Kharate A, Bhat P, et al. Isoniazid preventive therapy among children living with tuberculosis patients: is it working? A Mixed-Method study from Bhopal, India. J Trop Pediatr 2017;63:274-85.

152 Skinner D, Hesseling AC, Francis C, et al. It's hard work, but it's worth it: the task of keeping children adherent to isoniazid preventive therapy. Public Health Action 2013;3:191-8.

153 Skinner D, Mandalakas AM. Pasting together the preventive therapy puzzle. Int J Tuberc Lung Dis 2013;17:175-7.

154 Ngamvithayapong-Yanai J, Luangjina S, Thawthong S, et al. Stigma against tuberculosis may hinder non-household contact investigation: a qualitative study in Thailand. Public Health Action 2019;9:15-23.

155 Hirsch-Moverman Y, Mantell JE, Lebelo L, et al. Provider attitudes about childhood tuberculosis prevention in Lesotho: a qualitative study. BMC Health Serv Res 2020;20:461.

156 Aurum Institute. IMPAACT4TB: literature review to support the public health case for the scale-up of 3Hp, 2018. Available: https:// wwwimpaact4tborg/wp-content/uploads/2018/08/IMPAACT4TB PubHealthRationale_Report_v31_20180312-1pdf [Accessed 27 Feb 2021].

157 Elizabeth Glaser Pediatric AIDS Foundation and Unitaid. Catalyzing pediatric tuberculosis innovations (CaP TB): implementation and integration of new TB care and treatment models, 2018. Available: https://wwwpedaidsorg/wp-content/uploads/2018/04/Unitaid_ CaPTB-FactSheet_121818pdf [Accessed 27 Feb 2021].

158 Yuen CM, Millones AK, Puma D, et al. Closing delivery gaps in the treatment of tuberculosis infection: lessons from implementation research in Peru. PLoS One 2021;16:e0247411.

159 Yassin MA, Datiko DG, Tulloch O, et al. Innovative communitybased approaches doubled tuberculosis case notification and 
improve treatment outcome in southern Ethiopia. PLoS One 2013;8:e63174.

160 Barss L, Menzies D. Using a quality improvement approach to improve care for latent tuberculosis infection. Expert Rev Anti Infect Ther 2018;16:737-47.

161 Chakhaia T, Magee MJ, Kempker RR, et al. High utility of contact investigation for latent and active tuberculosis case detection among the contacts: a retrospective cohort study in Tbilisi, Georgia, 2010-2011. PLoS One 2014;9:e111773.

162 Do Nascimento Maia P, Sant'Anna CC. Tuberculosis contact tracing in children based on signs and simptoms. Pediatric Pulmonology 2016;51:S30.

163 Ilievska-Poposka B, Metodieva M, Zakoska M, et al. Latent Tuberculosis Infection - Diagnosis and Treatment. Open Access Maced J Med Sci 2018;6:651-5.

164 Machado A, Finkmoore B, Emodi K, et al. Risk factors for failure to complete a course of latent tuberculosis infection treatment in Salvador, Brazil. Int J Tuberc Lung Dis 2009;13:719-25.

165 Soussi G, Berraies A, Sahnoun I. Descriptive study of children with household contact of tuberculosis. Eur Resp J 2013;42.

166 Bennett RJ, Brodine S, Waalen J, et al. Prevalence and treatment of latent tuberculosis infection among newly arrived refugees in San Diego County, January 2010-October 2012. Am J Public Health 2014;104:e95-102

167 Blumberg EJ, Hovell MF, Kelley NJ, et al. Self-report INH adherence measures were reliable and valid in Latino adolescents with latent tuberculosis infection. J Clin Epidemiol 2005;58:645-8.

168 Bright-Thomas R, Nandwani S, Smith J, et al. Effectiveness of 3 months of rifampicin and isoniazid chemoprophylaxis for the treatment of latent tuberculosis infection in children. Arch Dis Child 2010;95:600-2

169 Catho G, Sénéchal A, Ronnaux-Baron A-S, et al. [Children exposed to multidrug-resistant tuberculosis: How should we manage? Analysis of 46 child contacts and review of the literature]. Rev Pneumol Clin 2015;71:335-41.
170 Cheng TL, Ottolini M, Getson P, et al. Poor validity of parent reading of skin test induration in a high risk population. Pediatr Infect Dis $J$ 1996;15:90-2.

171 Erkens CGM, de Vries G, Keizer ST, et al. The epidemiology of childhood tuberculosis in the Netherlands: still room for prevention. BMC Infect Dis 2014;14:295

172 Fathoala B, Evans MR, Campbell IA, et al. Active surveillance for tuberculosis in Wales: 1996-2003. Arch Dis Child 2006;91:900-4.

173 Higuchi K, Okada K, Harada N, et al. [Effects of prophylaxis on QuantiFERON TB-2G responses among children]. Kekkaku 2008;83:603-9.

174 Iroh Tam PY, Menon A, Butler K. A review of tuberculosis-related referrals among children in Ireland. Ir J Med Sci 2010;179:251-4.

175 Levesque JF, Dongier P, Brassard P, et al. Acceptance of screening and completion of treatment for latent tuberculosis infection among refugee claimants in Canada. Int J Tuberc Lung Dis 2004;8:711-7.

176 Lobato MN, Royce SE, Mohle-Boetani JC. Yield of source-case and contact investigations in identifying previously undiagnosed childhood tuberculosis. Int J Tuberc Lung Dis 2003;7:S391-6.

177 Lobato MN, Sun SJ, Moonan PK, et al. Underuse of effective measures to prevent and manage pediatric tuberculosis in the United States. Arch Pediatr Adolesc Med 2008;162:426-31.

178 Martínez-Roig A, Sánchez-Sánchez X, Torruella M. Compliance with tuberculostatic therapy among patients seen at hospital del MAR in Barcelona. Ten-year follow-up. Pediatria Catalana 2003;63:7-12.

179 Sentís A, Vasconcelos P, Machado RS, et al. Failure to complete treatment for latent tuberculosis infection in Portugal, 2013-2017: geographic-, sociodemographic-, and medical-associated factors. Eur J Clin Microbiol Infect Dis 2020;39:647-56.

180 Spruijt I, Erkens C, Suurmond J, et al. Implementation of latent tuberculosis infection screening and treatment among newly arriving immigrants in the Netherlands: a mixed methods pilot evaluation. PLoS One 2019;14:e0219252.

181 Starr M, Sawyer SM, Carlin JB, et al. A novel approach to monitoring adherence to preventive therapy for tuberculosis in adolescence. J Paediatr Child Health 1999;35:350-4. 